\title{
CO Reductive Oligomerization by a Divalent Thulium Complex and $\mathrm{CO}_{2}$-Induced Functionalization
}

Thomas Simler, ${ }^{a *}$ Karl N. McCabe, ${ }^{\mathrm{b}}$ Laurent Maron, ${ }^{\mathrm{b}}$ and Grégory Nocton ${ }^{\mathrm{a} *}$

a) LCM, CNRS, Ecole polytechnique, Institut polytechnique de Paris, Route de Saclay, 91120 Palaiseau, France. E-mail: thomas.simler@polytechnique.edu; gregory.nocton@polytechnique.edu

b) LPCNO, UMR 5215, Université de Toulouse-CNRS, INSA, UPS, Toulouse, France.

\begin{abstract}
To date, only a very limited number of complexes based on low-valent main group or f-block elements have allowed the reductive coupling of $\mathrm{CO}$ molecules to afford multicarbon oxygenates. Herein, we described the reactivity of the divalent thulium complex $\left[\mathrm{Tm}\left(\mathrm{Cp}^{\mathrm{ttt}}\right)_{2}\right] \quad\left(\mathrm{Cp}^{\mathrm{ttt}}=1,2,4\right.$-tris $($ tertbutyl)cyclopentadienyl) towards $\mathrm{CO}$, leading to selective $\mathrm{CO}$ reductive dimerization and trimerization into ethynediolate $\left(C_{2}\right)$ and ketenecarboxylate $\left(C_{3}\right)$ complexes, respectively. Quantum chemical (DFT) calculations were performed to shed light on the elementary steps of CO homologation and support a stepwise chain growth from the $C_{2}$ to the $C_{3}$ product upon addition of extra $\mathrm{CO}$. The attempted decoordination of the ethynediolate fragment by treatment with $\mathrm{Me}_{3} \mathrm{Sil}$ led to dimerization and rearrangement into a 3,4-dihydroxyfuran-2-one complex. Investigation of the reactivity of the $C_{2}$ and $C_{3}$ complexes towards other electrophiles led to unusual functionalization reactions: while the reaction of the ketenecarboxylate $C_{3}$ complex with electrophiles yielded new multicarbon oxygenated complexes, the addition of $\mathrm{CO}_{2}$ to the ethynediolate $\mathrm{C}_{2}$ complex resulted in the formation of a very reactive intermediate, allowing $\mathrm{C}-\mathrm{H}$ activation of the toluene solvent. This original intermolecular reactivity corresponds to an unprecedented functionalization of $\mathrm{CO}$-derived ligands, which is induced by $\mathrm{CO}_{2}$.
\end{abstract}




\section{Introduction}

Owing to environmental and economic reasons, the transformation and valorization of abundant and readily available chemical feedstock such as $\mathrm{CO}$ and $\mathrm{CO}_{2}$ are very topical goals. ${ }^{1}$ Carbon monoxide is a $\mathrm{C}_{1}$ gas that is used in the industrial production of organic feedstock molecules such as methanol ${ }^{2}$ and acetic acid. ${ }^{3}$ Synthesis gas (syn-gas: $\mathrm{CO} / \mathrm{H}_{2}$ ) is converted into liquid hydrocarbons and oxygenates on industrial scales by using the Fischer-Tropsch $(\mathrm{F}-\mathrm{T})$ process. ${ }^{4}$ As the $\mathrm{C} \equiv 0$ triple bond is one of the strongest chemical bonds (bond dissociation energy of $1075 \mathrm{~kJ} \cdot \mathrm{mol}^{-1}$ ), ${ }^{5}$ this process typically operates under harsh temperature and pressure conditions $\left(200-350^{\circ} \mathrm{C}, 20-45\right.$ bars) using heterogeneous transition metal catalysts $(\mathrm{Fe}, \mathrm{Co}) .{ }^{6}$ The precise mechanism in the formation of $\mathrm{F}-\mathrm{T}$ products is still under debate and, to gain more insight into the elementary steps involved, several organometallic complexes have been used as soluble models. ${ }^{7}$ Similarly, recent advances in transition-metal-free F-T chemistry have been reported, describing formation of growing carbon chains. ${ }^{8}$

Although $\mathrm{CO}$ homologation has been observed by the coupling between two or more fragments upon insertion of $\mathrm{CO}$ into metal-alkyl, ${ }^{9}$-aryl, ${ }^{10}$-hydride, ${ }^{11}$-imide ${ }^{12}$ or -boryl bonds, ${ }^{13}$ the direct reductive coupling of $\mathrm{CO}$ molecules has only been achieved by a very limited number of systems, typically involving low-valent oxophilic-metallic or non-metallic-elements. ${ }^{14}$ For example, homogeneous $p-{ }^{15}$, and d-block compounds ${ }^{16}$ have been used to promote $\mathrm{CO}$ reductive coupling. Molecular low-valent $\mathrm{f}$-block complexes based on $\mathrm{U}(\mathrm{III})$ and $\mathrm{Ln}(\mathrm{II})$ metal centers have shown very promising reactivity in the reductive coupling of $\mathrm{CO}$, which can be traced back to their highly reducing character and oxophilic nature. ${ }^{17}$ Detailed experimental $\left.\right|^{17 d-f, 17 j}$ and computational studies ${ }^{17 f, 18}$ have been performed by Cloke, Green, Maron and coworkers in order to rationalize the CO reductive coupling reactivity by bulky U(III) sandwich complexes. Depending on the reaction conditions and steric bulk of the supporting ligands, selective formation of oxocarbon dianions of the type ethynediolate (A), deltate (B) or squarate (C) was reported (Figure 1). DFT calculations pointed to a "zig-zag" intermediate complex featuring a bridging trans-bent $\left[\mathrm{C}_{2} \mathrm{O}_{2}\right]^{2-}$ dianion as a key intermediate in the formation of the different species. A similar intermediate was also recently suggested by Jones and co-workers in the reductive coupling of $\mathrm{CO}$ using activated $\beta$-diketiminate $\mathrm{Mg}(\mathrm{I})$ complexes (Figure 1). ${ }^{15 e, 15 g}$ However, in these studies, the reactivity of the $\mathrm{CO}$ oligomerization products was not further explored. Very recently, Crimmin and co-workers described the sequential formation of $\mathrm{C}_{1}-\mathrm{C}_{4}$ chain compounds starting from $\mathrm{CO}$ and $\mathrm{CO}_{2}$ feedstocks in the presence of transition metal carbonyl complexes and using $\beta$-diketiminate $\mathrm{Al}(\mathrm{I})$ reductants. ${ }^{15 c, 15 \mathrm{k}}$ Other systems allowing sequential chain growth by reductive homologation of $\mathrm{CO}$ from isolable intermediates are exceedingly rare, ${ }^{15 a}$ and, to the best of our knowledge, have not been used in further functionalization reactions. 

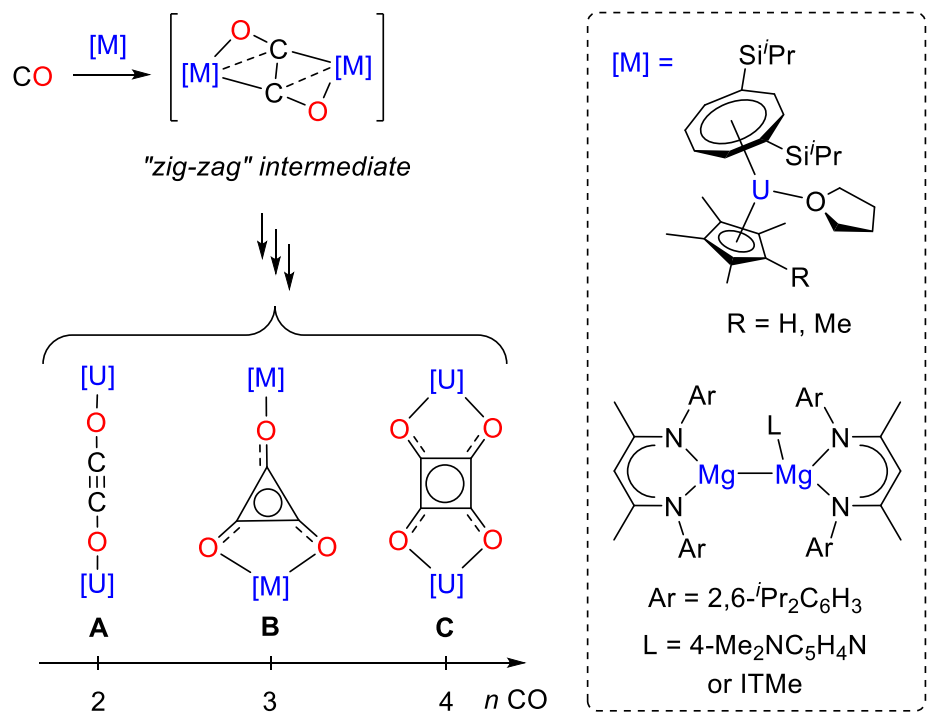

Figure 1. Evolution of the "zig-zag" intermediate into $\mathrm{CO}$ oligomerization products upon reaction of selected $\mathrm{U}(\mathrm{III})$ and $\mathrm{Mg}(\mathrm{I})$ complexes with $\mathrm{CO}$ (ITMe = 1,3,4,5-tetramethylimidazol-2-ylidene).

We have been interested in the use of highly reducing $\operatorname{Tm}(I I)^{19}$ and other divalent lanthanide complexes for homogeneous transformations and small molecule activation. ${ }^{20}$ Herein, we report the reactivity of the $\mathrm{Tm}(\mathrm{II})$ complex $\left[\mathrm{Tm}\left(\mathrm{Cp}^{\mathrm{ttt}}\right)_{2}\right]^{21}\left(\mathrm{Cp}^{\mathrm{ttt}}=1,2,4\right.$-tris(tert-butyl)cyclopentadienyl) towards CO, leading to selective $\mathrm{CO}$ reductive di- and trimerization products. The reactivity of the corresponding complexes, which feature central dianionic $\left\{\mathrm{C}_{n} \mathrm{O}_{n}\right\}^{--}(n=2,3)$ oxocarbon moieties, was systematically investigated towards electrophiles $\left(\mathrm{CO}_{2}\right.$, silylating/alkylating agents). Novel multicarbon oxygenated frameworks were obtained through unusual reactivities, opening new avenues for the functionalization of $\mathrm{CO}$ and $\mathrm{CO}_{2}$.

\section{Results and Discussion}

\section{Synthesis and structure of 1}

The divalent thulium complex $\left[\mathrm{Tm}\left(\mathrm{Cp}^{\mathrm{ttt}}\right)_{2}\right](\mathbf{1})$ was obtained by slightly modifying the original procedure by Nief and co-workers, ${ }^{21}$ in order to ensure better reproducibility and a higher isolated yield (for details, see the Supporting Information). Crystals of 1 suitable for X-ray diffraction (XRD) studies could be successfully obtained from a concentrated pentane solution of the complex at low temperature $\left(-40^{\circ} \mathrm{C}\right)$. Owing to the very high solubility of $\mathbf{1}$ in hydrocarbon solvents, only the crystal structure of the less soluble THF adduct was reported in the seminal publication. ${ }^{21 a}$ The molecular structure of $\mathbf{1}$ in the solid state (Figure 2) confirmed the formation of the base-free complex with two independent molecules of 1 in the asymmetric unit, displaying very similar metrical data. 


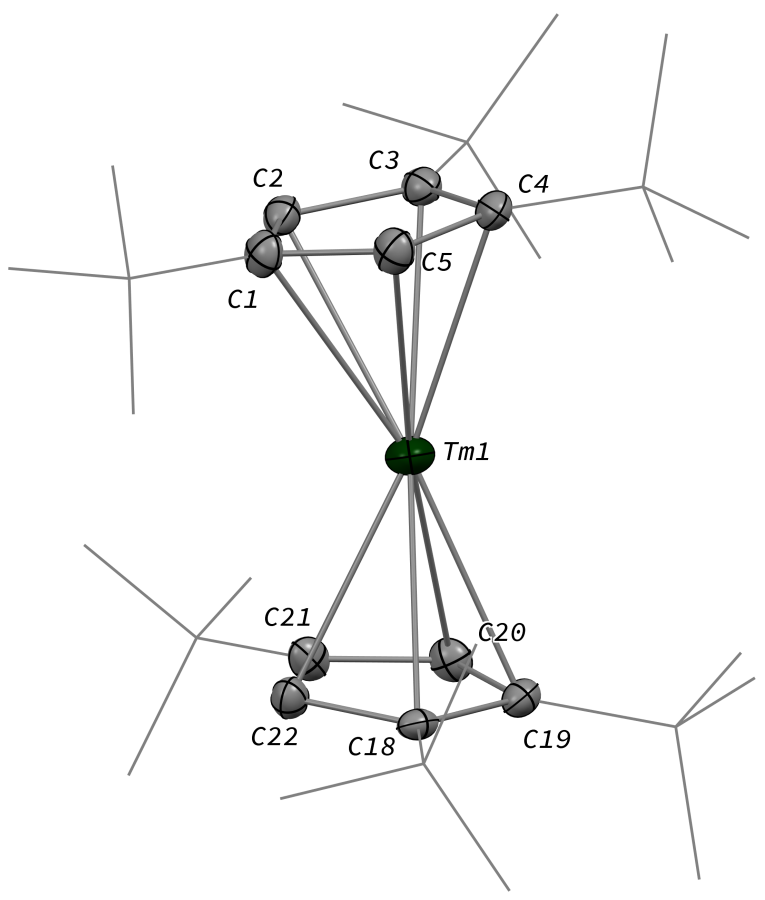

Figure 2. Molecular structure of one of the two independent molecules of $\mathbf{1}$ in the solid state with thermal ellipsoids at the $40 \%$ probability level (except for the ${ }^{t} \mathrm{Bu}$ groups depicted in wireframe). Only one disordered position for the ${ }^{t} \mathrm{Bu}$ groups has been depicted and $\mathrm{H}$ atoms have been omitted for clarity. Selected bond distances (Å): Tm1-C1 2.712(4), Tm1-C2 2.676(4), Tm1-C3 2.681(4), Tm1-C4 2.664(4), Tm1-C5 2.670(4), Tm1-C18 2.673(4), Tm1-C19 2.677(4), Tm1-C20 2.686(4), Tm1-C21 2.703(4), Tm1-C22 2.658(4).

In this divalent lanthanide sandwich complex, the $\operatorname{Tm}(I 1)$ metal center is surrounded by two $\eta^{5}$ coordinated $\mathrm{Cp}^{\mathrm{ttt}}$ ligands with Tm-C bonds ranging from 2.652(4) to 2.717(4) $\AA$ (in average $2.68 \pm 0.02 \AA$ ) and $\mathrm{Tm}-\mathrm{Cp}$ (ctr) (ctr = ring centroid) distances of $c a .2 .39 \AA$ (see also Table S3). In each crystallographically independent molecule, the sum of $\mathrm{Tm}-\mathrm{Cp}$ (ctr) distances is $c a .4 .78 \AA$, a value only slightly larger than that in the trivalent complex $\left[\mathrm{Tm}\left(\mathrm{Cp}^{\mathrm{ttt}}\right)_{2}\right)$ ( $4.74 \AA$, see Table S3). Although the metal center in $\mathbf{1}$ is only surrounded by two $\mathrm{Cp}^{\text {ttt }}$ ligands, a slightly bent arrangement is observed in the solid state, with angles between the mean $\mathrm{C}_{5}$ planes in the range $11.0-13.9^{\circ}$ and $\mathrm{Cp}(\mathrm{ctr})-\mathrm{Tm}-\mathrm{Cp}(\mathrm{ctr})$ angles of $164.3-167.7^{\circ}$. Similar bent arrangements were observed for the base-free complexes $\left[\operatorname{Ln}\left(C p^{t t t}\right)_{2}\right](\operatorname{Ln}=\mathrm{Sm}, \mathrm{Eu}),{ }^{22}$ although 1 presents a $\mathrm{Cp}$ (ctr)-Ln-Cp(ctr) arrangement closer to linearity, which may be the result of the smaller ionic radius of $\mathrm{Tm}$ (II) compared to Sm(II) (1.03 and $1.17 \AA ̊$, respectively, in a six-coordinate environment). ${ }^{23}$ Consistently, the $\mathrm{Ln}-\mathrm{Cp}$ (ctr) distance is $c a .0 .13 \AA$ shorter in 1 in comparison to that in $\left[\mathrm{Sm}\left(\mathrm{Cp} \mathrm{Ctt}_{2}\right]\right.$ (see Table S3).

Despite the established high reducing character of $\operatorname{Tm}(I I)$ complexes, $^{19,24}$ no reaction of 1 was observed with either $\mathrm{N}_{2}$ or $\mathrm{H}_{2}$ and no traces of decomposition could be noticed upon heating a $\mathrm{C}_{6} \mathrm{D}_{6}$ solution of the complex at $80{ }^{\circ} \mathrm{C}$ for several days. This unusual stability contrasts with the reported reactivity of base-free samarocene $\left[\mathrm{SmCp}_{2}{ }_{2}\right]\left(\mathrm{Cp}^{*}=\eta^{5}-\mathrm{C}_{5} \mathrm{Me}_{5}\right)$ with $\mathrm{N}_{2}{ }^{25}$ The bulky nature of the $\mathrm{Cp}^{\mathrm{ttt}}$ ligand 
is vital to kinetically stabilize the $\operatorname{Tm}(I I)$ complex and avoid thermal decomposition, as observed when using the smaller $\mathrm{Cp}^{*}$ or disubstituted 1,2- $\mathrm{R}_{2} \mathrm{C}_{5} \mathrm{H}_{3}\left(\mathrm{R}={ }^{\mathrm{t}} \mathrm{Bu}, \mathrm{SiMe}_{3}\right)$ ligands ${ }^{26}{ }^{26}$ Despite the steric protection imposed by the $\mathrm{Cp}^{\text {ttt }}$ ligands, coordination of a Lewis base to the metal center has been achieved in related $\left[\mathrm{Ln}\left(\mathrm{Cp}^{\mathrm{ttt}}\right)_{2}\right]$ complexes $(\mathrm{Ln}=\mathrm{Yb}$ and $\mathrm{Sm}) \cdot{ }^{22 a, 22 b}$ We therefore reasoned than the high reducing character of the $\operatorname{Tm}$ (II) center ${ }^{19,27}$ in $\mathbf{1}$ in addition to the oxophilic nature of $f$-elements ${ }^{28}$ may lead to interesting reactivity towards the gaseous oxocarbons $\mathrm{CO}$ and $\mathrm{CO}_{2}$.

\section{Reactivity of 1 towards $C O$}

Addition of $\mathrm{CO}$ to a degassed solution of $\mathbf{1}$ in toluene led to an immediate color change from deep purple to light brown. Depending on the reaction conditions, more precisely the stoichiometry in $\mathrm{CO}$, two different complexes were isolated (Scheme 1).

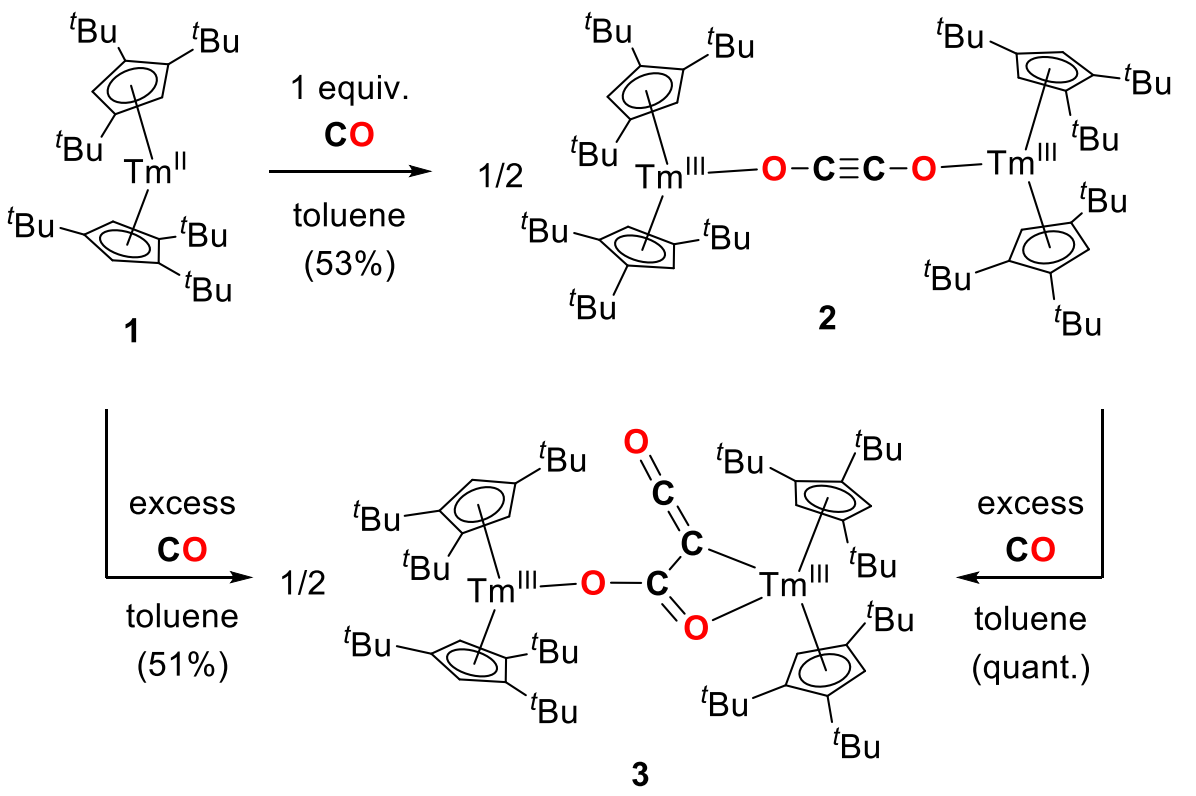

Scheme 1. Synthesis of the CO dimerization and trimerization products $\mathbf{2}$ and $\mathbf{3}$.

When the reaction was performed using one molar equivalent of $\mathrm{CO}$ per $\mathbf{1}$, the $\mathrm{CO}$ dimerization product $\mathbf{2}$ was isolated in 53\% crystalline yield. The molecular structure of $\mathbf{2}$ in the solid state (Figure 3) was unambiguously confirmed by XRD studies and revealed the formation of the dinuclear complex $\left[\mathrm{Tm}\left(\mathrm{Cp}^{\mathrm{ttt}}\right)_{2}\right]_{2}\left(\mu-\kappa(O): \kappa\left(O^{\prime}\right)-\mathrm{C}_{2} \mathrm{O}_{2}\right)$ featuring a bridging ethynediolate ligand between the two oxidized $\mathrm{Tm}(\mathrm{III})$ metal centers. The $\mathrm{C}-\mathrm{C}$ bond distance in the $\mathrm{C}_{2} \mathrm{O}_{2}{ }^{2-}$ moiety of $1.226(10) \AA$ is within the typical range for related ethynediolate bridged dimers of $\mathrm{f}$-block elements, ${ }^{16 e, 17 f-j, 171}$ and is consistent with a $\mathrm{C} \equiv \mathrm{C}$ triple bond. The Tm-O-C angles of $146.7(5)$ and $151.9(5)^{\circ}$ depart from linearity and the Tm-O bond distances of 2.066(5) and 2.078(5) $\AA$ are at the long end of the range reported for Tm(III) complexes featuring terminal alkoxy ligands (from ca. 1.96 to $2.09 \AA$ A). ${ }^{29}$ In line with the oxidation of the thulium metal center from the 
+ II to the +III oxidation state, the sum of the two $\mathrm{Tm}-\mathrm{Cp}(\mathrm{ctr})$ separations for each metal center in $\mathbf{2}$, in the range $4.69-4.71 \AA$, is ca. $0.08 \AA$ shorter than that in 1 .

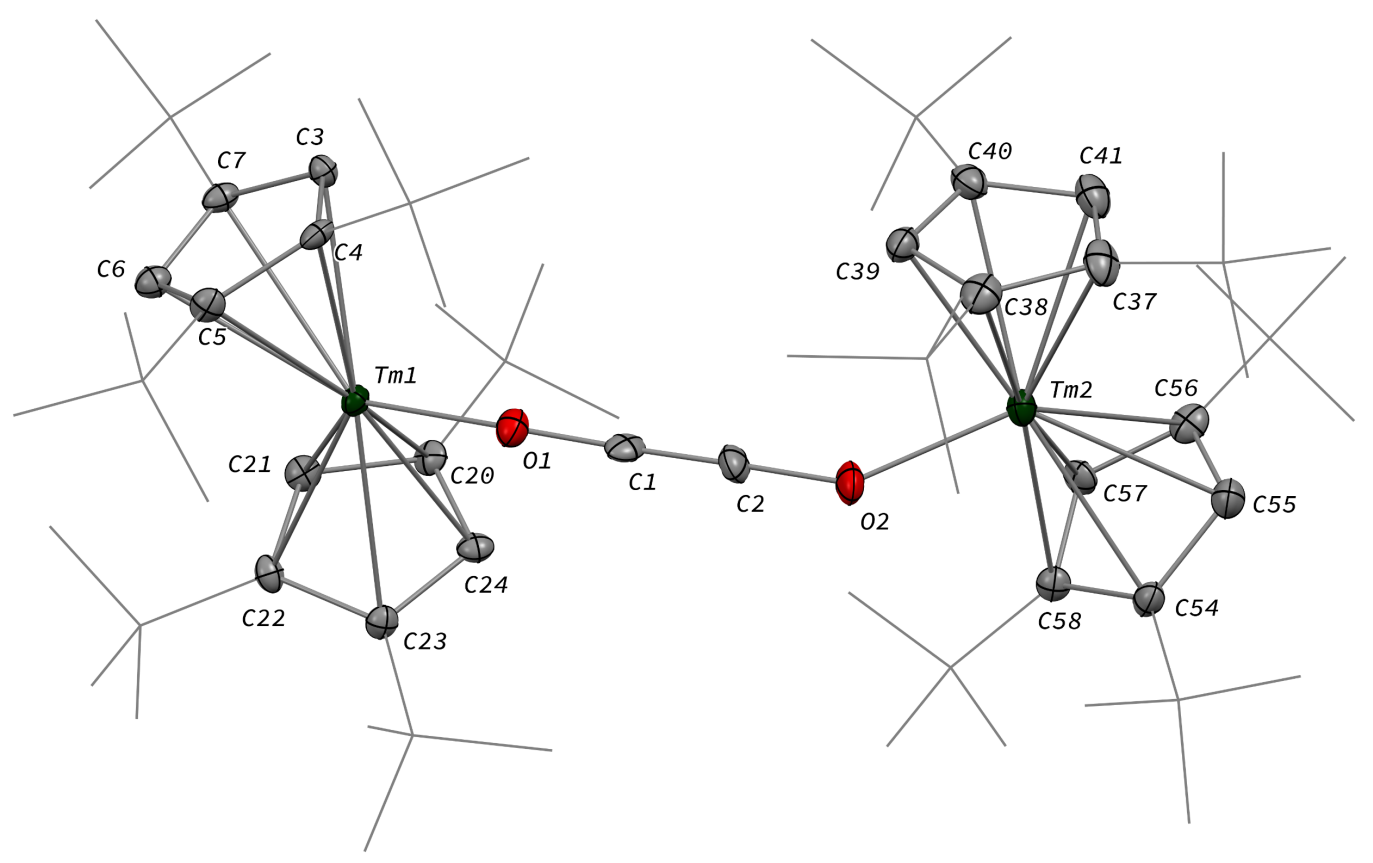

Figure 3. Molecular structure of $\mathbf{2}$ in the solid state with thermal ellipsoids at the $40 \%$ probability level (except for the ${ }^{t} \mathrm{Bu}$ groups depicted in wireframe). $\mathrm{H}$ atoms have been omitted for clarity. Selected bond distances (Å) and angles [ [ ${ }^{\circ}$ : C1-C2 1.226(10), C1-O1 1.265(9), C2-O2 1.296(9), Tm1-O1 2.066(5), Tm2O2 2.078(5); C2-C1-O1 178.4(8), C1-C2-O2 178.1(9), C1-O1-Tm1 151.9(5), C2-O2-Tm2 146.7(5).

Analysis of the ${ }^{1} \mathrm{H}$ NMR spectrum of $\mathbf{2}$ in toluene- $d_{8}$ revealed only very broad resonances at room temperature, possibly resulting from a fluxional behavior of the $\mathrm{Cp}^{\mathrm{ttt}}$ ligands. ${ }^{20 \mathrm{a}, 22 \mathrm{~b}} \mathrm{~A}$ better resolved spectrum featuring three broad resonances at $\delta \approx 171,32$ and $2 \mathrm{ppm}$ was obtained upon recording the spectrum at $80^{\circ} \mathrm{C}$ (see Figures $\mathrm{S} 2-\mathrm{S} 3$ ), and is consistent with free rotation of the $\mathrm{Cp}^{\mathrm{ttt}}$ ligands leading to an overall $D_{2 h}$ symmetric species in solution at high temperature. In the IR spectrum of $\mathbf{2}$, no significant absorption band was observed in the range $1500-2800 \mathrm{~cm}^{-1}$, all the more so in the expected region for $\mathrm{C} \equiv \mathrm{C}$ triple bonds, which can be explained by the IR selection rules (lack of change in the molecular dipole). The isotopically labelled complex $\left[\mathrm{Tm}\left(\mathrm{Cp}^{\mathrm{ttt}}\right)_{2}\right]_{2}\left(\mu-\kappa(O): \kappa\left(O^{\prime}\right)-{ }^{13} \mathrm{C}_{2} \mathrm{O}_{2}\right)\left(2-{ }^{13} \mathrm{C}\right)$ was obtained by the same procedure using ${ }^{13} \mathrm{C}$-enriched ${ }^{13} \mathrm{CO}$. As expected, the IR spectra of $\mathbf{2}$ and $2-{ }^{13} \mathbf{C}$ are nearly identical (see Figure S32), one only notable difference being the band at $1329 \mathrm{~cm}^{-1}$ in 2 that is red-shifted to $1304 \mathrm{~cm}^{-1}$ upon ${ }^{13} \mathrm{C}$ labelling. The corresponding absorption band can be confidently assigned to the $\mathrm{C}-\mathrm{O}$ stretching vibration, as the experimental ratio between these numbers, 1.019 , compares well with the theoretical value of 1.023 obtained from reduced mass considerations. Owing to highly paramagnetic nature of Tm(III) complexes, no ${ }^{13} \mathrm{C}$ NMR resonances could be detected, even for the isotopically enriched $2-{ }^{13} \mathrm{C}$.

The formation of ethynediolate fragments upon reductive coupling of $\mathrm{CO}$ has been reported for a handful of low-valent f-block complexes, mostly based on $\mathrm{U}(\mathrm{III})$ metal centers, ${ }^{16 e, 17 f-j, 171}$ and recently by Evans and co-workers upon treatment of in situ generated $\operatorname{Ln}(\mathrm{II})$ species or $\left[\mathrm{K}(18-\mathrm{c}-6)_{2}\right]\left[\mathrm{Tm}\left\{\mathrm{N}\left(\mathrm{SiMe}_{3}\right)_{2}\right\}_{3}\right]$ 
with $\mathrm{CO}^{16 e, 171}$ The sensitivity of the corresponding ethynediolate products to thermolysis was found to be ligand dependent. ${ }^{17 \mathrm{~g}-\mathrm{i}}$ In the case of $\mathbf{2}$, no traces of decomposition could be detected upon heating a toluene solution of the complex at $100{ }^{\circ} \mathrm{C}$ for several days.

In contrast to the formation of $\mathbf{2}$, the reaction of $\mathbf{1}$ with excess $\mathrm{CO}$ led to the $\mathrm{CO}$ trimerization product $\left[\mathrm{Tm}\left(\mathrm{Cp}^{\mathrm{ttt}}\right)_{2}\right]_{2}\left(\mu-\kappa(O): \kappa^{2}\left(C, O^{\prime}\right)-\mathrm{C}_{2} \mathrm{O}_{3}\right)(3)$ isolated in $51 \%$ crystalline yield (Scheme 1$)$. The isotopically labelled complex $\left[\mathrm{Tm}\left(\mathrm{Cp}^{\mathrm{ttt}}\right)_{2}\right]_{2}\left(\mu-\kappa(O): \mathrm{K}^{2}\left(\mathrm{C}, \mathrm{O}^{\prime}\right)-{ }^{13} \mathrm{C}_{2} \mathrm{O}_{3}\right)\left(3-{ }^{13} \mathrm{C}\right)$ was obtained analogously using ${ }^{13} \mathrm{C}$-enriched carbon monoxide. The $\mathrm{X}$-ray structure of 3 confirmed the formation of a ketenecarboxylate $\left(\mathrm{O}_{2} \mathrm{C}-\mathrm{C}=\mathrm{C}=\mathrm{O}\right)^{2-}$ fragment bridging the two $\mathrm{Tm}$ (III) centers (Figure 4). The reductive trimerization of $\mathrm{CO}$ into such a motif has previously only been described in two reports by Evans and co-workers using reducing lanthanide complexes based on $\mathrm{Cp}^{*}$ ligands. ${ }^{17 \mathrm{a}, 17 \mathrm{~b}}$ The Tm-C bond distances in 3, ranging from 2.601(6) to 2.769(6) $\AA$ (in average $2.67 \pm 0.06 \AA$ ) (see also Table S4) are slightly longer than those observed in $\mathbf{2}$, which may be the result of the larger steric demand of the $\left(\mu-\kappa(O): \kappa^{2}\left(C, O^{\prime}\right)-C_{2} O_{3}\right)^{2-}$ bridging ligand. The latter is coordinated to the two Tm metal centers via a bridging carboxylate unit (Tm2-02 2.307(5), Tm1-03 2.098(5) $\AA$ ) and further coordinated to Tm2 with a Tm2-C2 bond distance of 2.473(7) $\AA$. The sum of the bonding angles around $\mathrm{C} 2\left(359.6^{\circ}\right)$ is pointing to a planar arrangement for $\mathrm{C} 1, \mathrm{C} 2, \mathrm{C} 3$ and $\mathrm{Tm} 2$. In the ketenecarboxylate fragment, the bond distances within the ketene moiety (C1-C2 1.284(10) $\AA$, C1-O1 1.181(9) $\AA$ ) are indicative of double bonds while the adjacent C2-C3 bond is much longer (1.430(9) $\AA$ ) and in the range of single $\mathrm{C}-\mathrm{C}$ bonds. The carboxylate $\mathrm{C} 3-\mathrm{O} 2$ and $\mathrm{C} 3-\mathrm{O} 3$ bond distances of $1.261(8)$ and 1.296(8) Å, respectively, are very similar, supporting a delocalized negative charge over the carboxylate moiety. Overall, the metrical data within the ketenecarboxylate fragment are in good agreement with those previously reported by Evans and co-workers, the only major structural difference lying in the coordination mode of the trimerized $\mathrm{CO}$ unit. ${ }^{17 a, 17 b}$ While the $\left(\mathrm{O}_{2} \mathrm{C}-\mathrm{C}=\mathrm{C}=\mathrm{O}\right)^{2-}$ fragment is only bridging two $\operatorname{Tm}\left(\mathrm{Cp}^{\mathrm{ttt}}\right)_{2}$ subunits in 2, further dimerization and association into tetranuclear clusters were observed using the smaller $\mathrm{Cp} *$ ligands. ${ }^{17 a, 17 b}$ 


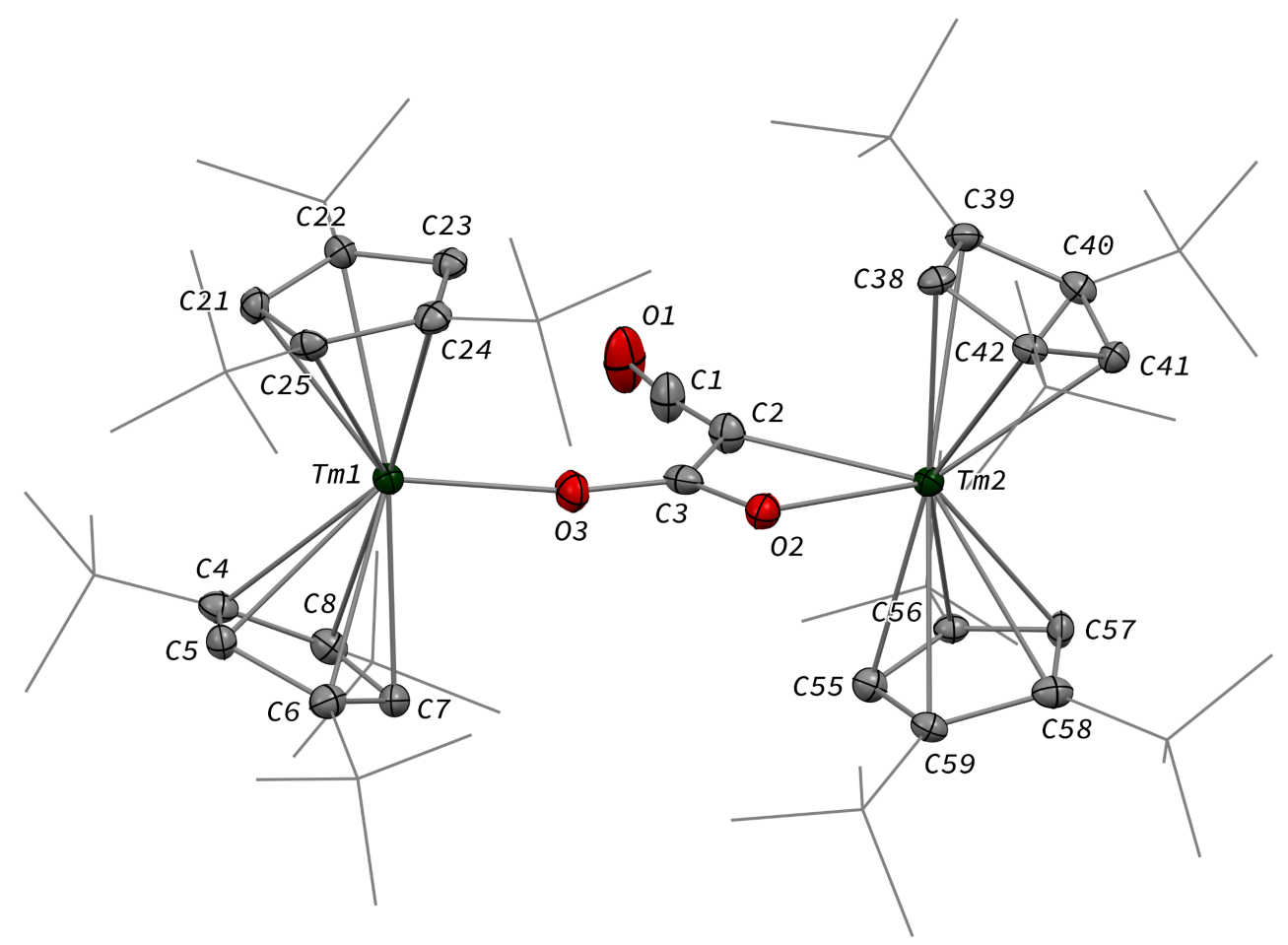

Figure 4. Molecular structure of $\mathbf{3}$ in the solid state with thermal ellipsoids at the $40 \%$ probability level (except for the ${ }^{t} \mathrm{Bu}$ groups depicted in wireframe). $\mathrm{H}$ atoms have been omitted for clarity. Selected bond distances (Å) and angles [ $\left.{ }^{\circ}\right]$ : O1-C1 1.181(9), O2-C3 1.261(8), O3-C3 1.296(8), C1-C2 1.284(10), C2-C3 1.430(9), Tm1-O3 2.098(5), Tm2-O2 2.307(5), Tm2-C2 2.473(7); C1-C2-C3 128.6(7), C3-O2-Tm2 99.2(4), C3-O3-Tm1 170.8(4), O1-C1-C2 172.2(8), O2-C3-C2 116.0(6), O3-C3-C2 123.5(6), C1-C2-Tm2 143.5(5), C3-C2-Tm2 87.5(4).

The ${ }^{1} \mathrm{H}$ NMR spectrum of $\mathbf{3}$ at room temperature revealed several broad resonances in the range $\delta-100$ to $400 \mathrm{ppm}$, as a result of the paramagnetic nature of the complex and restricted free rotation of the $\mathrm{Cp}^{\text {ttt }}$ ligands. ${ }^{20 a}$ Upon heating to $80^{\circ} \mathrm{C}$ (see Figure S5), a simpler baseline was observed featuring four main and relatively broad $\left(\Delta v_{1 / 2} \approx 1500-3200 \mathrm{~Hz}\right)$ resonances at $\delta 185,153,32$ and $-33 \mathrm{ppm}$, assigned to the ${ }^{t} \mathrm{Bu}$ groups. The number of signals and the corresponding integrations support free rotation of the $\mathrm{Cp}^{\text {ttt }}$ ligands at high temperature, resulting in an overall $C_{s}$ symmetry in solution. It should be noted that complex 3 was found to be thermally stable at least up to $110{ }^{\circ} \mathrm{C}$ in toluene solution. As a result of the highly paramagnetic nature of the complex, no signals could be observed in the ${ }^{13} \mathrm{C}\left\{{ }^{1} \mathrm{H}\right\} \mathrm{NMR}$ spectra of both 3 and ${ }^{3-13} \mathbf{C}$. In the IR spectrum of 3, a very strong absorption band was observed at $2066 \mathrm{~cm}^{-1}$ in the ketene region, shifting to $2003 \mathrm{~cm}^{-1}$ in $3-{ }^{13} \mathrm{C}$ upon ${ }^{13} \mathrm{CO}$ isotope labelling (See Figure S33). In order to confidently assign the corresponding absorption band, the vibrational spectra of $\mathbf{3}$ and ${ }^{-13} \mathbf{C}$ were calculated at the DFT level of theory (B3PW91, see details in the Supporting Information). In the computed spectra (Figures S55-S57), the asymmetric stretch of the O1-C1-C2 ketene fragment gives rise to an intense absorption band at $2190 \mathrm{~cm}^{-1}$ in $\mathbf{3}$ and $2121 \mathrm{~cm}^{-1}$ in $\mathbf{3}^{-13} \mathbf{C}$. Although the (uncorrected) computed values are ca. $120 \mathrm{~cm}^{-1}$ larger than the experimental ones, the ratios between the wavenumbers of two 
isotopologues (1.031 experimentally and 1.033 computationally) are almost identical, confirming the assignment of the band.

The overall reaction leading to the $\left(\mathrm{O}_{2} \mathrm{C}-\mathrm{C}=\mathrm{C}=\mathrm{O}\right)^{2-}$ fragment involves a reductive trimerization of $\mathrm{CO}$, more precisely the net transfer of two electrons from two Tm(II) centers to three molecules of CO. Since the central carbon atom ( $\mathrm{C} 2$, Figure 4$)$ in $\mathbf{3}$ presents no $\mathrm{C}-\mathrm{O}$ connectivity, complete cleavage of one $\mathrm{CO}$ triple bond has occurred. Although CO cleavage and further homologation is thought to occur in heterogeneous Fischer-Tropsch systems, such reactivity is not common in homogeneous systems. ${ }^{4 c, 7 b, 14 a}$

The observed CO reductive homologation induced by the $\operatorname{Tm}$ (II) complex 1, leading to the selective formation of either the ethynediolate complex $\mathbf{2}$ or the ketenecarboxylate complex $\mathbf{3}$, is the result of a fine balance between steric protection and coordinative unsaturation. A similar observation was already reported in the case of U(III) mixed-sandwich complexes reported by Cloke and co-workers, which allowed possible reductive $\mathrm{CO}$ di-, tri- or tetramerization depending on the steric demand of the supporting ligands and amount of $\mathrm{CO} .{ }^{17 \mathrm{j}}$ Since selective formation of the $\mathrm{CO}$ dimerized product $\mathbf{2}$ is observed in the presence of one molar equivalent of CO per Tm(II) center, we further examined whether $\mathbf{2}$ may be an intermediate in the formation of $\mathbf{3}$. In a control experiment, the reaction of isolated $\mathbf{2}$ in toluene solution with excess $\mathrm{CO}$ was monitored by paramagnetic ${ }^{1} \mathrm{H}$ NMR spectroscopy (see Figure S6), revealing clean and quantitative transformation into 3 . This reaction is relatively slow at room temperature, requiring $c a .1-2$ days to reach completion, which suggests a relatively high activation barrier. The gain further insights in the elementary steps leading to the formation of $\mathbf{2}$ and $\mathbf{3}$, i.e. the overall mechanism of this unusual reaction, DFT calculations were performed and confirmed that $\mathbf{2}$ appears indeed as an intermediate in the formation of 3 (see below). To the best of our knowledge, this result is unprecedented since all reported ethynediolate complexes have been either synthesized under excess of $\mathrm{CO},{ }^{15 j, 17 \mathrm{~g}^{-1,171}}$ or the isolated products were found inert towards external $\mathrm{CO}^{17 f}$ To date, systems allowing controlled carbon chain growth by sequential insertions of $\mathrm{CO}$ on isolated intermediates are exceedingly rare. Such examples include $\mathrm{CO}$ addition on the boron-boron triple bond of a diboryne compound described by the group of Braunschweig, ${ }^{15 a}$ and recent work by Crimmin and co-workers on systems based on transition metal carbonyls together with aluminum(I) reductants. ${ }^{15 c, 15 \mathrm{k}}$

Finally, to investigate whether other reaction conditions have an influence on the selectivity, temperature and solvent effects were examined. Performing the addition of $\mathrm{CO}$ at low temperature ($78^{\circ} \mathrm{C}$ ) or in different solvents (pentane, benzene, $\mathrm{Et}_{2} \mathrm{O}$ and THF) led to similar results signifying that the stoichiometry in $\mathrm{CO}$ is the only parameter controlling the selectivity in this reaction. It should be however noted that the reaction proceeds much more slowly in coordinating solvents such as THF, requiring several days until complete consumption of $\mathbf{1}$, which can be traced back to competitive coordination of THF and $\mathrm{CO}$ to the metal center. An inhibitory role of THF in the reduction of organic substrates by Sm(II) complexes has previously been observed in the literature. ${ }^{30}$ Interestingly, in the U(III) systems reported by Arnold and co-workers, THF coordination was found to completely stop the reactivity towards $\mathrm{CO}^{17 \mathrm{~g}, 17 \mathrm{~h}}$ Such a 
different behavior may originate in the steric demand of the $\mathrm{Cp}^{\text {ttt }}$ ligands that induces weak and reversible coordination of the usually strongly bound THF donor. ${ }^{21 a}$

\section{Mechanistic insights by DFT calculations}

The formation of complex $\mathbf{3}$ has been investigated at the DFT level (B3PW91) and the computed enthalpy profile at room temperature is depicted in Figure 5. The reaction begins with the side-on coordination of $\mathrm{CO}$ to 1 . This coordination induces the reduction of $\mathrm{CO}$ and the oxidation of $\mathrm{Tm}$ (II) to $\mathrm{Tm}(\mathrm{III})$, the radical on CO being stabilized by $\eta^{2}$ coordination to the metal center. This step is computed to be endothermic by $16.3 \mathrm{kcal}^{\mathrm{mol}}{ }^{-1}$. Unlike the calculated pathway for $\mathrm{CO}$ reductive coupling at U(III) mixed-sandwich complexes, $^{18 b}$ the $\mathrm{CO}$ moiety is not further reduced by the coordination of a second molecule of $\mathbf{1}$ but rather a radical coupling between two $\mathrm{Tm}(\mathrm{III})\left(\mathrm{CO}^{\circ}\right)$ fragments is observed. This step also contrasts with that calculated for $\mathrm{CO}$ reductive oligomerization on $\mathrm{Mg}(\mathrm{I})$ dimers where the addition of $\mathrm{CO}$ occurs sequentially. ${ }^{15,15 g, 15 j}$ It can be noted that a radical pathway for $\mathrm{CO}$ oligomerizations has been recently suggested on the basis of fragmentation reactions by mass spectrometry and computational quantum calculations on squarate species, i.e. CO tetramerization products. ${ }^{31}$ The associated transition state (TS1) has been located on the Potential Energy Surface (PES). The radical coupling barrier is $33.4 \mathrm{kcal}^{\mathrm{mol}}{ }^{-1} \mathrm{from}$ 1 (but only $17.1 \mathrm{kcal}^{\mathrm{mol}}{ }^{-1}$ from the Tm(III) intermediate complex) in line with a kinetically accessible reaction. The radical nature of the TS is highlighted by the computed unpaired spin densities (see Figure S48) where 0.6 unpaired electron is located on the two carbons that couple. Following the intrinsic reaction coordinate, the ethynediolate complex iso2 is obtained, which formation is favorable $\left(-9.0 \mathrm{kcal} . \mathrm{mol}^{-1}\right.$ with respect to 1). This ethynediolate complex displays a "zig-zag" geometry which is the key intermediate in this reactivity (see Figure 1) and is similar to the "zig-zag" intermediate suggested in previous studies. ${ }^{15 e, 15 g, 17 f, 17 g, 18 b}$ This intermediate can either yield the more stable linear structure corresponding to $\mathbf{2}$, or bind another CO molecule. In our case, these two possibilities are thermodynamically competitive (the CO coordination is exothermic by $29.4 \mathrm{kcal}^{\mathrm{mol}}{ }^{-1}$ from iso2 while the linear ethynediolate complex 2 is $35.2 \mathrm{kcal}^{\mathrm{mol}} \mathrm{l}^{-1}$ more stable than the "zig-zag" one). The formation of the stable CO adduct is easily explained by the nature of the HOMO of iso2, that can easily overlap with the $\pi^{*}$ orbital of CO (see Figure S49). From the CO adduct, a C-C coupling TS has been located and corresponds to a nucleophilic attack of the ethynediolate to the $\pi$ system of $\mathrm{CO}$ (see the HOMO at the TS in Figure S50). The associated barrier is low $\left(17.0 \mathrm{kcal} . \mathrm{mol}^{-1}\right)$, yielding a stable ketene-type intermediate $\left(-43.8 \mathrm{kcal} / \mathrm{mol}^{-1}\right)$. This ketene intermediate can isomerize with a barrier of $37.7 \mathrm{kcal}^{\mathrm{mol}}{ }^{-1}$ (TS3) to form complex 3 (see details in the Supporting Information), which is the most stable complex of the entire profile $\left(-111.3 \mathrm{kcal}^{\mathrm{mol}} \mathrm{m}^{-1}\right)$. The relatively high activation barrier calculated for TS3 is consistent with a relatively slow (1-2 days) transformation of $\mathbf{2}$ to $\mathbf{3}$ in the presence of excess $\mathrm{CO}$ at room temperature. 


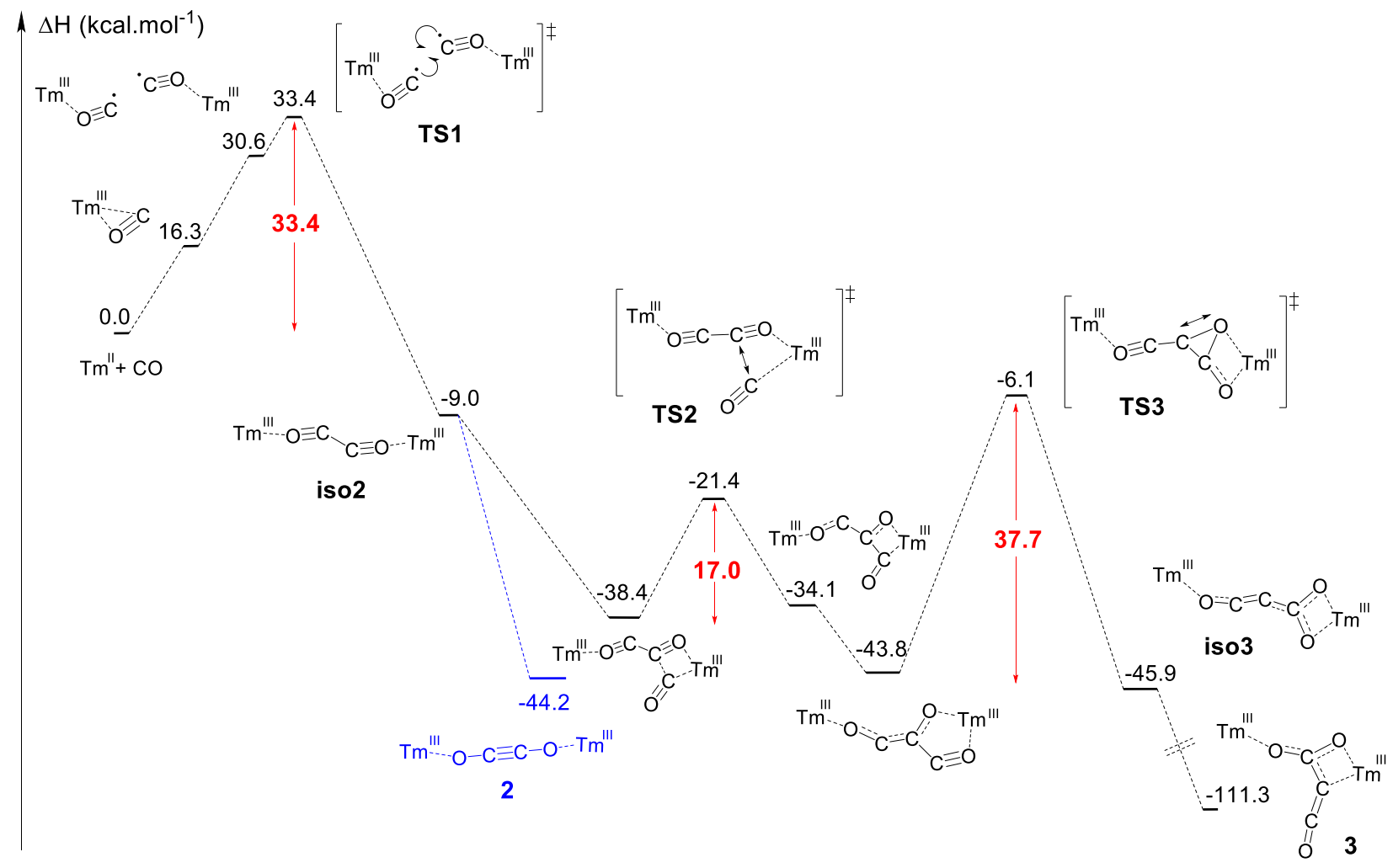

Figure 5. Computed enthalpy profile at room temperature for the formation of $\mathbf{3}$

\section{Reactivity of 1 towards $\mathrm{CO}_{2}$}

The reactivity of the $\mathrm{Tm}(\mathrm{II})$ complex 1 was also investigated towards $\mathrm{CO}_{2}$ as divalent lanthanide complexes have been reported to yield oxalate and/or carbonate complexes upon reduction of $\mathrm{CO}_{2}{ }^{32}$ The reaction of 1 with excess $\mathrm{CO}_{2}$ led to the formation of the carbonate complex 4 (Scheme 2 ) isolated in $72 \%$ yield. Its IR spectrum features a strong absorption band at $1430 \mathrm{~cm}^{-1}$, assigned to $\mathrm{C}-\mathrm{O}$ stretching in the coordinated carbonate ligand. ${ }^{33}$ The ${ }^{1} \mathrm{H}$ NMR spectra of 4 at variable temperatures (Figure S8) show multiple broad, overlapping and paramagnetically shifted resonances as a sign of restricted free rotation of the $\mathrm{Cp}^{\text {ttt }}$ ligands. $^{22 b}$
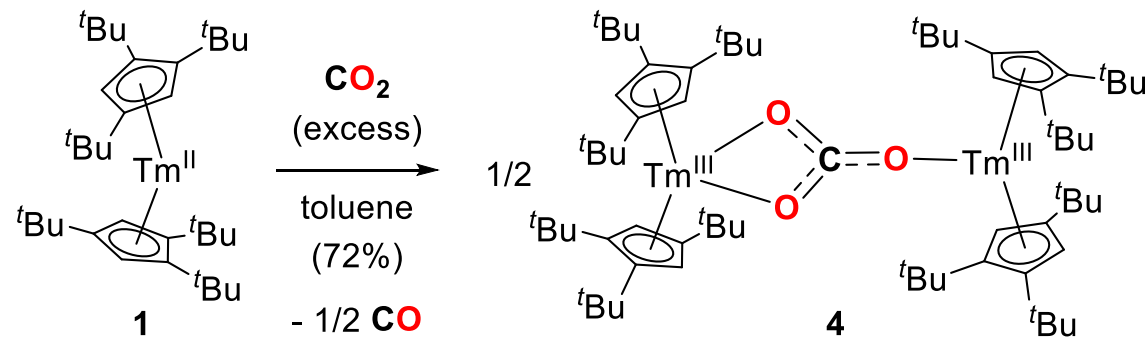

Scheme 2. Reaction of $\mathbf{1}$ with $\mathrm{CO}_{2}$ leading to the formation of the carbonate complex 4 .

The molecular structure of the complex (see Figure S38), as established by X-ray diffraction studies, confirmed the presence of a bridging carbonate ligand with a $\mu-\kappa(O): \kappa^{2}\left(O^{\prime}, O^{\prime \prime}\right)$ coordination mode between 
the two $\mathrm{Tm}^{\mathrm{III}}\left(\mathrm{Cp}^{\mathrm{ttt}}\right)_{2}$ fragments, as previously observed for the $\mathrm{Sm}(\mathrm{III})$ analogue $\left[\mathrm{Sm}\left(\mathrm{Cp}^{\mathrm{ttt}}\right)_{2}\left(\mathrm{CO}_{3}\right)\right] \cdot{ }^{20 a} A$ more detailed description of the structure can be found in the Supporting Information.

\section{Reactivity of $\mathbf{3}$ towards electrophiles}

Having complex $\mathbf{3}$ at hand with a reproducible procedure and in decent isolated yield, we investigated its reactivity towards electrophiles. Indeed, the ketenecarboxylate complex $\mathbf{3}$ presents a polarized lanthanide-carbon bond, which is prone to further functionalization or insertion reactions. ${ }^{32,34}$ It should be noted that, for the two previously reported ketenecarboxylate complexes based on $\operatorname{Ln}\left(C p^{*}\right)_{2}(\operatorname{Ln}=\operatorname{La}$, $\mathrm{Sm}$ ) fragments, ${ }^{17 a, 17 b}$ no study of their reactivity was described.

The reaction of 3 with $\mathrm{CO}_{2}$ in toluene- $d_{8}$ proceeded instantaneously and cleanly at room temperature, as evidenced by paramagnetic ${ }^{1} \mathrm{H}$ NMR monitoring of the reaction. The corresponding product 5 was isolated in $82 \%$ yield (Scheme 3) and crystallographically characterized.

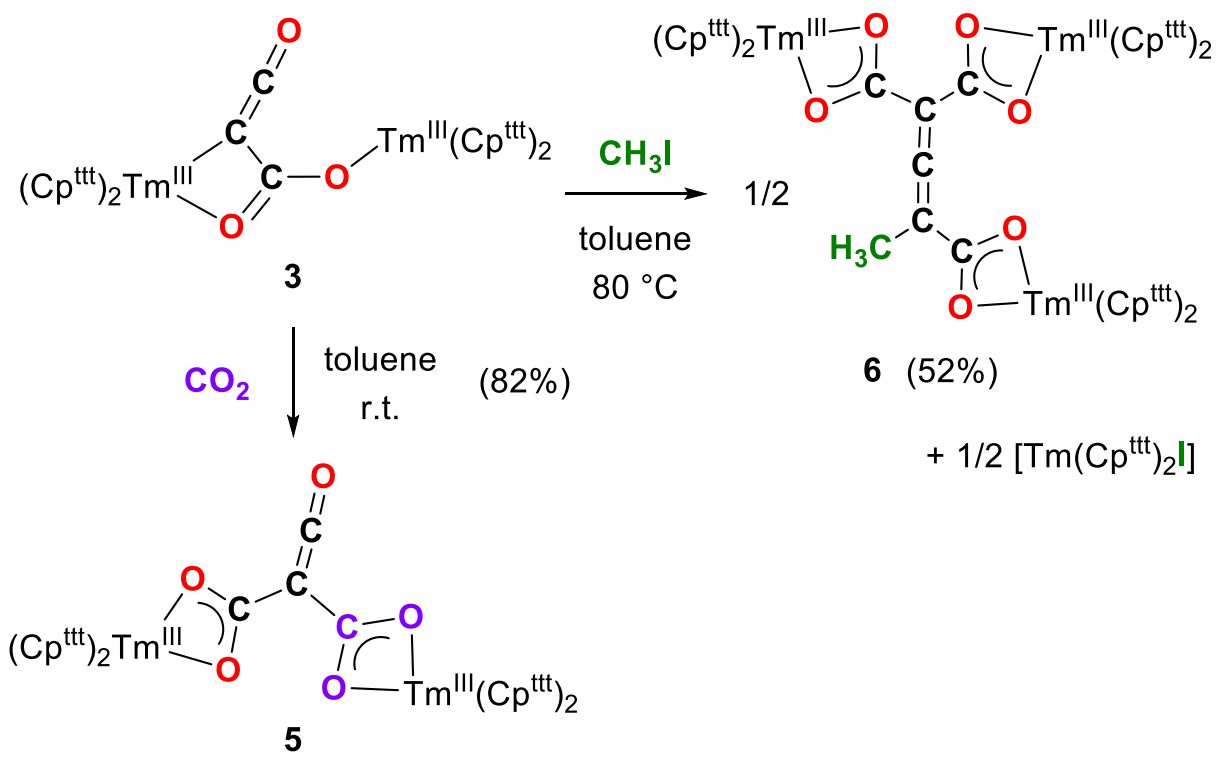

Scheme 3. Reactivity of $\mathbf{3}$ towards $\mathrm{CO}_{2}$ and Mel.

Analysis of the molecular structure of $\mathbf{5}$ in the solid state (Figure 6) revealed the insertion of $\mathrm{CO}_{2}$ in the $\mathrm{Tm}-\mathrm{C}$ bond of $\mathbf{3}$, yielding a nearly planar bridging $\mu-\kappa^{2}(O): \kappa^{2}(O)$-ketenedicarboxylate ligand. The two $\mathrm{Tm}$ (III) centers are each surrounded by a chelating carboxylate group and two $\eta^{5}$-coordinated $\mathrm{Cp}^{\text {ttt }}$ ligands. The $\mathrm{C}-\mathrm{C}$ bond distances between the ketene and carboxylate groups are identical within experimental

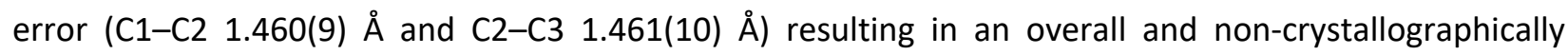
imposed $C_{2 v}$ symmetry (not taking into account the substitution patterns on the $\mathrm{Cp}^{\text {ttt }}$ ligands). The $\mathrm{C} 2-\mathrm{C} 4$ and O5-C4 bond distances, 1.343(10) and 1.142(10) $\AA$, respectively, are consistent with double bonds and a ketene fragment, and are similar to the corresponding distances in 3 ( $\mathrm{C} 1-\mathrm{C} 2$ and $\mathrm{O} 1-\mathrm{C} 1$ bond distances of $1.284(10)$ and 1.181(9) $\AA$, respectively). The sums of the two Tm-Cp(ctr) separations for both metal centers in 5 are 4.735 and $4.746 \AA$, with $\mathrm{Tm}-\mathrm{C}$ bond distances ranging from 2.618(7) to 2.733(7) $\AA$ (in average $2.66 \pm 0.04 \AA$ ) (See also Table S4). 
The ${ }^{1} \mathrm{H}$ NMR spectrum of 5 in toluene- $d_{8}$ revealed several six main broad and paramagnetically shifted resonances at room temperature (see Figures S9-S10), resulting from restricted rotation of the $\mathrm{Cp}^{\text {ttt }}$ ligands around the metal center. Upon heating to $60^{\circ} \mathrm{C}$, the spectrum evolved into three very broad $\left(\Delta v_{1 / 2} \approx 10000-17000 \mathrm{~Hz}\right)$ resonances at $\delta-16,51$ and $197 \mathrm{ppm}$, which is in agreement with freely rotating $\mathrm{Cp}^{\mathrm{ttt}}$ ligands and an overall $C_{2 v}$ symmetric species in solution. In the IR spectrum of $\mathbf{5}$, two intense bands were detected at 2157 and $2146 \mathrm{~cm}^{-1}$, assigned to the asymmetric ketene stretching vibration, ${ }^{35}$ along with an intense absorption band at $1572 \mathrm{~cm}^{-1}$ corresponding to the asymmetric stretching of the coordinated carboxylate groups. ${ }^{36}$

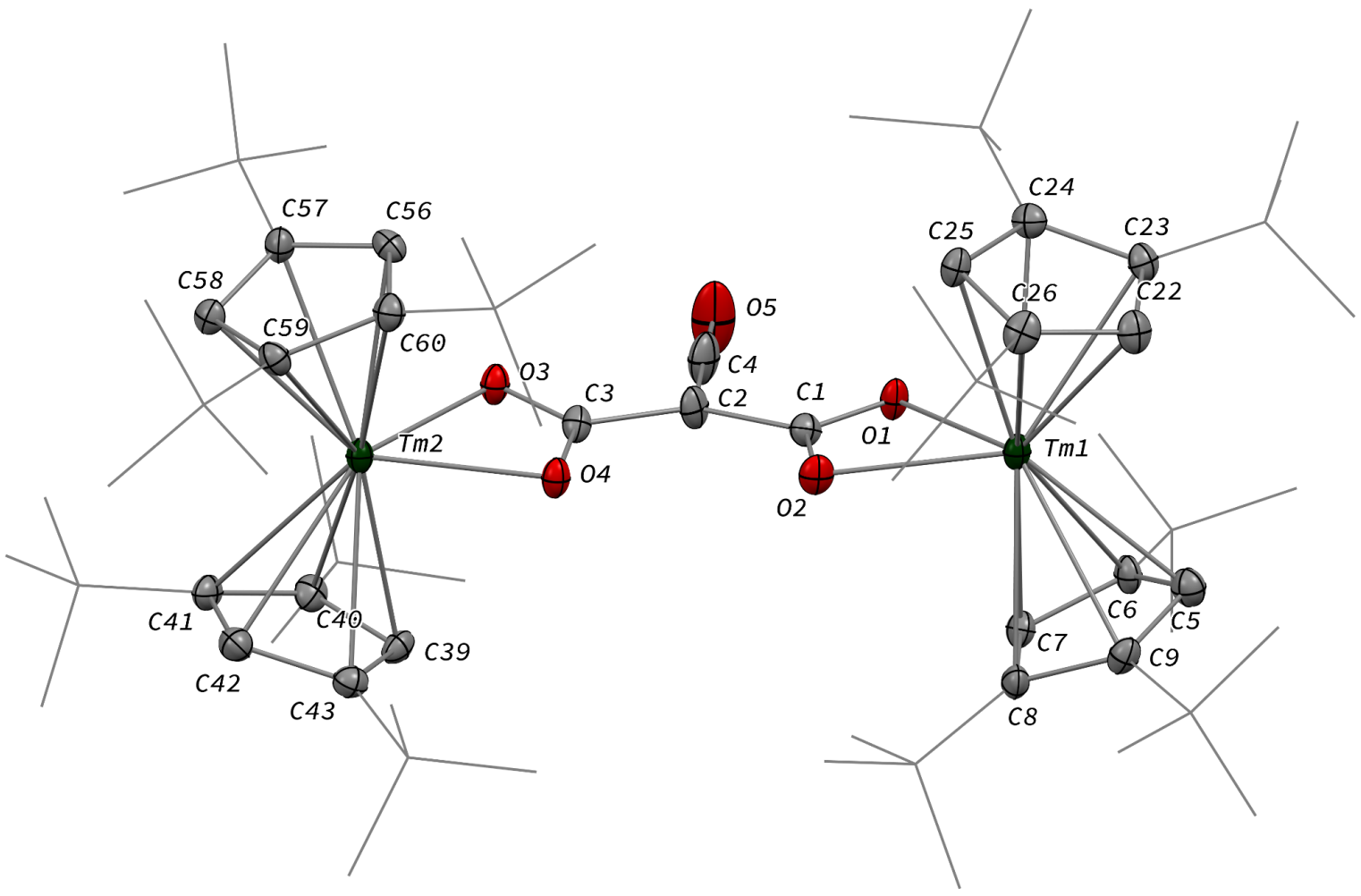

Figure 6. Molecular structure of $\mathbf{5}$ in the solid state with thermal ellipsoids at the $40 \%$ probability level (except for the ${ }^{t} \mathrm{Bu}$ groups depicted in wireframe). $\mathrm{H}$ atoms have been omitted for clarity. Selected bond distances (Å) and angles [ [ $]$ : Tm1-01 2.282(5), Tm1-O2 2.354(5), Tm2-03 2.305(5), Tm2-04 2.318(5), 01C1 1.283(8), O2-C1 1.263(8), O3-C3 1.273(8), O4-C3 1.267(8), O5-C4 1.142(10), C1-C2 1.460(9), C2-C3 1.461(10), C2-C4 1.343(10); O1-Tm1-O2 56.9(2), O3-Tm2-O4 57.0(2), O1-C1-C2 116.0(6), O2-C1-O1 120.3(6), O2-C1-C2 123.6(6), C1-C2-C3 131.7(6), C1-C2-C4 113.0(7), C3-C2-C4 115.3(6), O3-C3-C2 118.1(6), O3-C3-O4 120.5(6), O4-C3-C2 121.4(6), O5-C4-C2 178.5(10).

Although 3 was found to react with $\mathrm{Me}_{3} \mathrm{SiCl}$ upon heating to $60^{\circ} \mathrm{C}$, no crystals suitable for XRD studies could be obtained to unambiguously assign the nature of the products formed. When the reaction was performed using Mel as electrophile (Scheme 3), no reaction occurred at room temperature but slow conversion of 3 was observed in toluene- $d_{8}$ upon heating the reaction mixture at $80{ }^{\circ} \mathrm{C}$ for 3 days. Paramagnetic ${ }^{1} \mathrm{H}$ NMR monitoring of the reaction revealed the formation $\left[\operatorname{Tm}\left(C \mathrm{p}^{\mathrm{ttt}}\right)_{2} l\right]$, identified by comparison with the ${ }^{1} \mathrm{H}$ NMR spectrum of an authentic sample, along with a new set of signals (see Figure S13). After evaporation of the solvent, the crude product was washed several times with pentane to 
remove $\left[\operatorname{Tm}\left(C p^{t t t}\right)_{2} l\right]$. Recrystallization of the remaining solid from hot toluene afforded crystals of 6 suitable for XRD studies. Its molecular structure (Figure 7) features a trinuclear Tm(III) complex in which each thulium center is coordinated by a chelating carboxylate group and two $\eta^{5}$-coordinated $\mathrm{Cp}^{\text {ttt }}$ ligands. The C2-C4 and C4-C5 bond distances in 6 of 1.300(6) and 1.325(5) $\AA$, respectively, together with the almost linear $\mathrm{C} 2-\mathrm{C} 4-\mathrm{C} 5$ arrangement (bonding angle of $\left.172.2(4)^{\circ}\right)$, are consistent with $\mathrm{C}=\mathrm{C}$ double bonds in an allene-type structure. In contrast, the $\mathrm{C} 1-\mathrm{C} 2, \mathrm{C2}-\mathrm{C} 3, \mathrm{C} 5-\mathrm{C} 6$ and $\mathrm{C} 5-\mathrm{C} 7$ bonds, with distances from $1.486(6)$ to $1.512(5) \AA$, are in the typical range for $\mathrm{C}-\mathrm{C}$ single bonds. The carbon atoms $\mathrm{C} 2$ and $\mathrm{C} 5$ present a trigonal planar geometry (sum of the bonding angles around C2 and C5 of 360.0 and $359.3^{\circ}$ ), consistent with $\mathrm{sp}^{2}$ hybridization. The Tm-O bond distances in 6, in the range $2.299(3)-2.333(3) \AA$, are similar to those observed in the dicarboxylate complex 5 (from 2.282(5) to 2.354(5) Å).
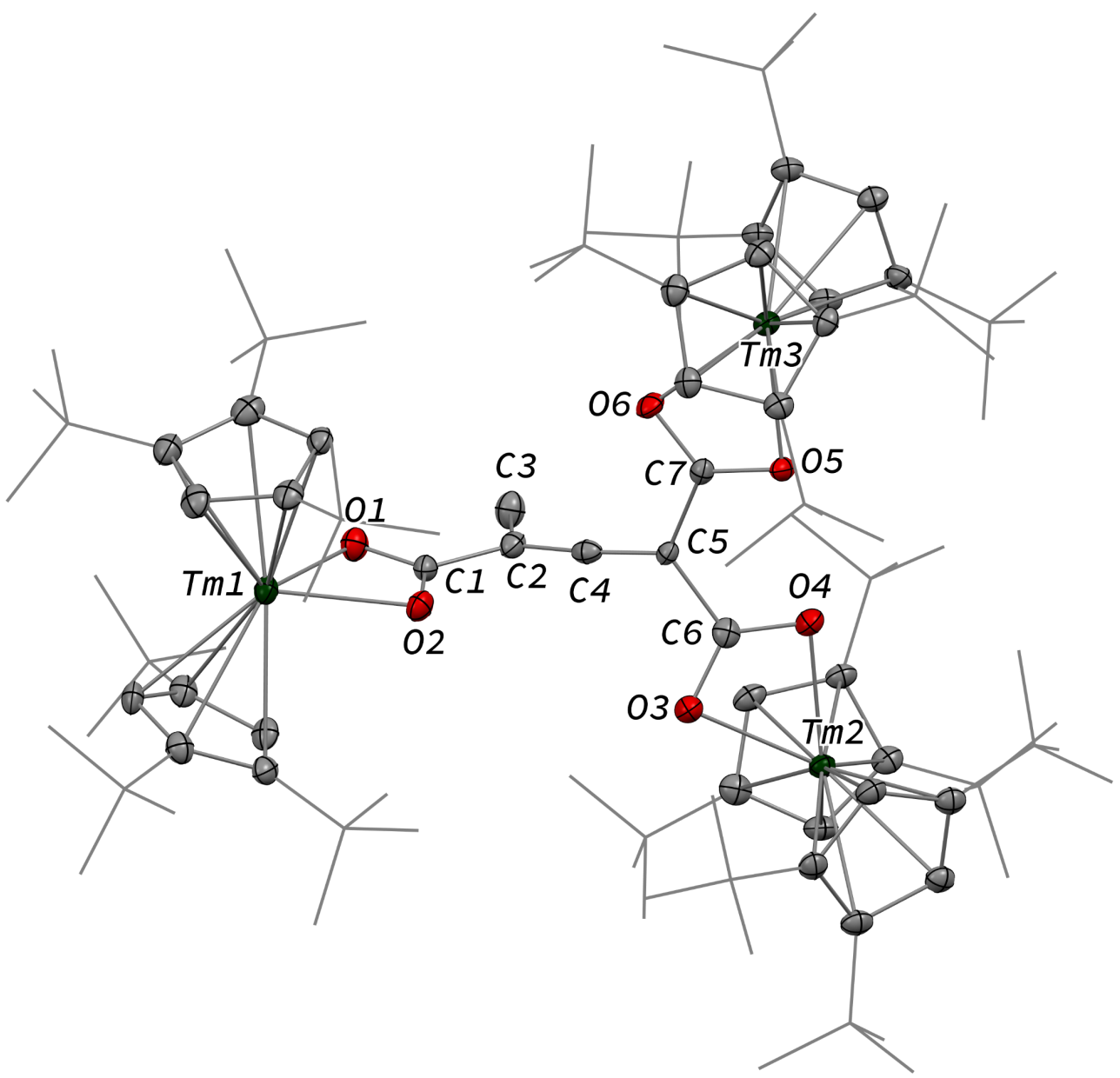

Figure 7. Molecular structure of 6 in the solid state with thermal ellipsoids at the $40 \%$ probability level (except for the ${ }^{t} \mathrm{Bu}$ groups depicted in wireframe). $\mathrm{H}$ atoms have been omitted for clarity. Selected bond distances ( $\AA$ ) and angles [ ${ }^{\circ}$ ]: Tm1-01 2.299(3), Tm1-02 2.315(3), Tm2-03 2.319(3), Tm2-04 2.307(3), Tm3-05 2.304(3), Tm3-06 2.333(3), 01-C1 1.274(5), O2-C1 1.268(5), O3-C6 1.284(5), O4-C6 1.269(5), O5-C7 1.271(4), O6-C7 1.268(4), C1-C2 1.486(6), C2-C3 1.501(6), C2-C4 1.300(6), C4-C5 1.325(5), C5-C6 1.512(5), C5-C7 1.492(5); O1-Tm1-O2 56.88(10), O3-Tm2-04 57.64(10), O5-Tm3-06 57.01(9), O1-C1C2 118.1(4), O1-C1-O2 119.6(4), O2-C1-C2 122.2(4), C1-C2-C3 116.6(4), C1-C2-C4 121.1(4), C3-C2-C4 122.3(4), C2-C4-C5 172.2(4), C4-C5-C6 117.6(3), C4-C5-C7 119.4(3), C6-C5-C7 122.3(3), O3-C6-C5 118.2(4), O3-C6-O4 121.8(4), O4-C6-C5 119.9(3), O5-C7-C5 119.7(3), O5-C7-O6 121.4(4), O6-C7-C5 119.0(3). 
The ${ }^{1} \mathrm{H}$ NMR spectra of 6 in the $20-80{ }^{\circ} \mathrm{C}$ temperature range display a complex pattern of paramagnetically shifted signals (Figure S12), as a result of the non-symmetric nature of the complex. In the IR spectrum of 6, the intense absorption band at $1583 \mathrm{~cm}^{-1}$ corresponds to the asymmetric stretching band of the coordinated carboxylate groups, similarly to the absorption band observed in $\mathbf{5}$. In addition, a weak band is observed at $1938 \mathrm{~cm}^{-1}$ and assigned to the asymmetric $\mathrm{C}=\mathrm{C}=\mathrm{C}$ stretching vibration. ${ }^{36}$

Although the mechanism for the formation of 6 is elusive to date and involves several rearrangement steps, the observed reactivity finds its origin in the reactive $\mathrm{Tm}-\mathrm{C}$ bond in $\mathbf{3}$. It should be stressed that the stoichiometry of the reaction is strictly respected as one equivalent of both 6 and $\left[\mathrm{Tm}\left(\mathrm{Cp}^{\mathrm{ttt}}\right)_{2} \mathrm{l}\right]$ are formed from two equivalents of 3 , in other words, one tris-anionic $\left\{\mathrm{MeC}_{3}\left(\mathrm{CO}_{2}\right)_{3}\right\}^{3-}$ framework and one iodide ligand are the result of the reaction of two di-anionic $\left\{\mathrm{C}_{3} \mathrm{O}_{3}\right\}^{2-}$ fragments with one molecule of Mel. Overall, this reaction corresponds to an unprecedented oligomerization and functionalization of $\mathrm{CO}$ through formation of an allene-tricarboxylate complex in which the $\left\{\mathrm{C}_{6} \mathrm{O}_{3}\right\}$ core exclusively arises from six $\mathrm{CO}$ molecules.

\section{$\underline{\text { Reactivity of } 2 \text { towards electrophiles }}$}

Intrigued by the reactivity of $\mathbf{3}$ towards electrophiles, we examined the reactivity of $\mathbf{2}$ towards $\mathrm{CO}_{2}$ and silyl electrophiles. The reactivity of $\mathbf{2}$ was investigated towards silylating agents to evaluate the possibility of decoordination and liberation of the anionic oxocarbon ligand. It should be noted that decoordination of $\mathrm{CO}$ reduction products from oxophilic U(IV) metal centers has been successfully achieved upon treatment with silyl electrophiles. ${ }^{17 i, 17 j, 37}$ No reaction occurred upon addition of excess $\mathrm{Me}_{3} \mathrm{SiCl}$ to 2 , even upon heating to $80^{\circ} \mathrm{C}$. In contrast, the addition of Me $\mathrm{M}_{3} \mathrm{SiOTf}$ to a solution of $\mathbf{2}$ in toluene- $d_{8}$ led to a complete conversion after $15 \mathrm{~h}$ at room temperature (Scheme 4). Analysis of the crude product by paramagnetic ${ }^{1} \mathrm{H}$ NMR spectroscopy revealed resonances corresponding to $\left[\mathrm{Tm}\left(\mathrm{Cp}^{\mathrm{ttt}}\right)_{2} \mathrm{OTf}\right]$ (8), identified by comparison with the ${ }^{1} \mathrm{H}$ NMR spectrum of an authentic sample of 8 (see Supporting Information and Figure S16), along with a new set of paramagnetically shifted signals. Crystallization from a concentrated pentane solution afforded yellow crystals of $\mathbf{7}$ suitable for XRD studies. Analysis of its molecular structure (Figure 8) revealed an unusual CO tetramerization product featuring a deprotonated 3,4-dihydroxyfuran2-one moiety bridging two Tm(III) metal centers. 


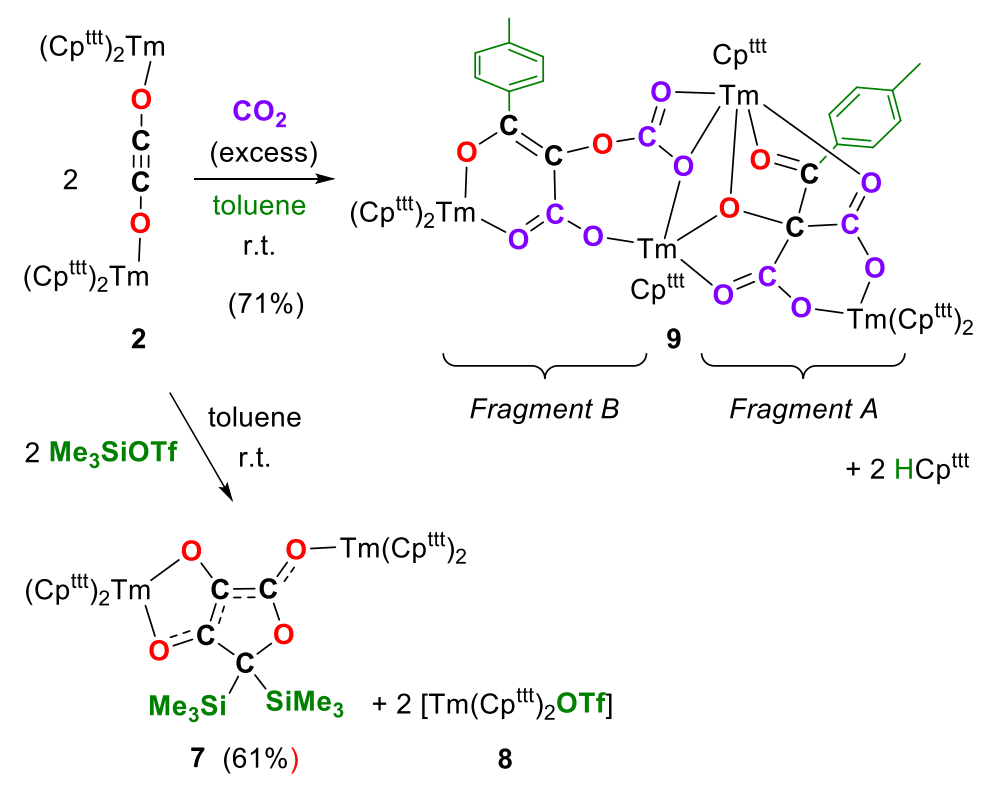

Scheme 4. Reaction of 2 with $\mathrm{CO}_{2}$ and $\mathrm{Me}_{3} \mathrm{SiOTf}$.

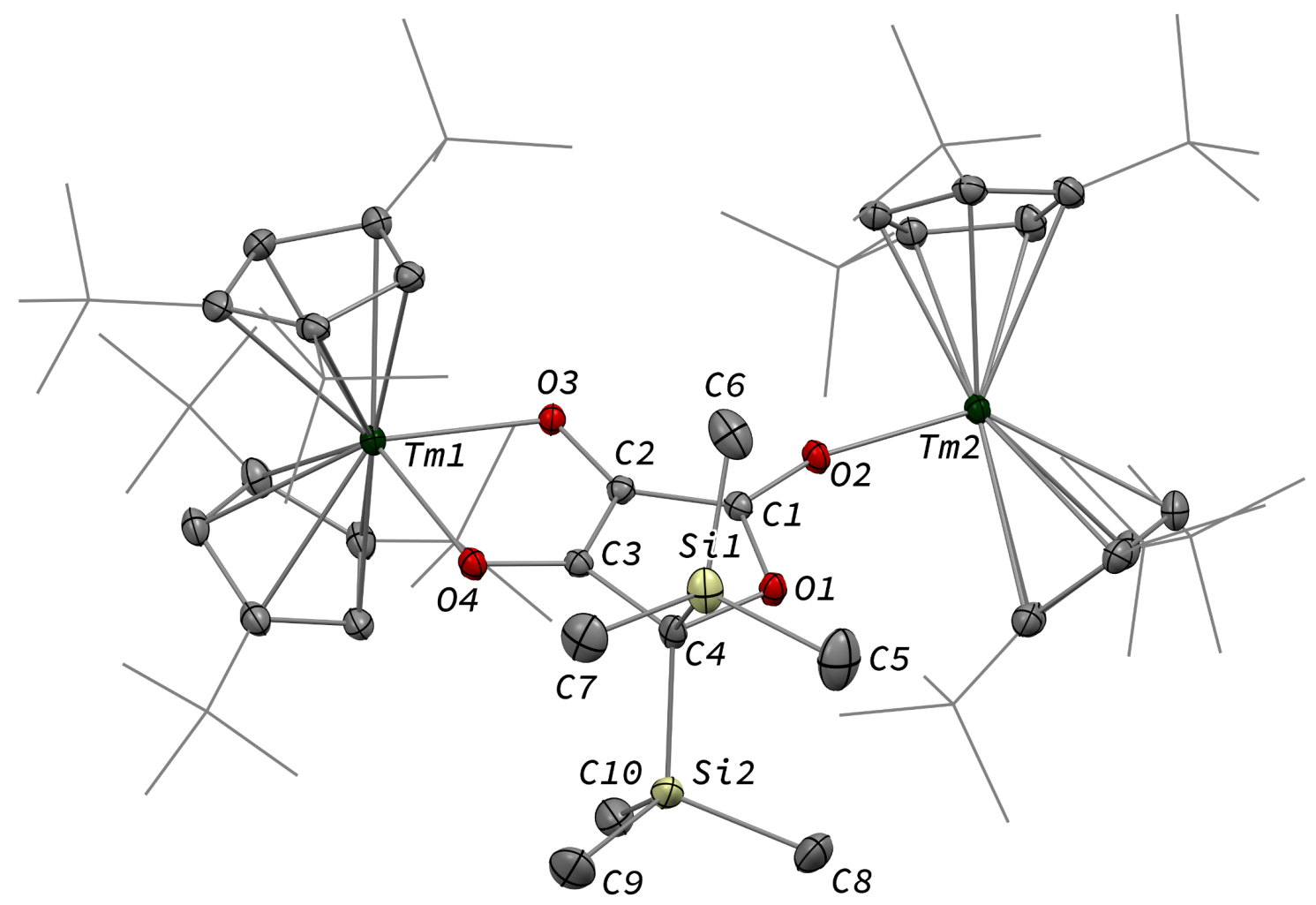

Figure 8. Molecular structure of $\mathbf{7}$ in the solid state with thermal ellipsoids at the $40 \%$ probability level (except for the ${ }^{t} \mathrm{Bu}$ groups depicted in wireframe). $\mathrm{H}$ atoms have been omitted for clarity. Selected bond distances (Å) and angles [ $\left.{ }^{\circ}\right]$ : Tm1-O3 2.200(2), Tm1-O4 2.333(2), Tm2-O2 2.146(2), O1-C1 1.368(3), O1C4 1.486(3), O2-C1 1.280(3), O3-C2 1.339(3), O4-C3 1.290(3), C1-C2 1.397(3), C2-C3 1.396(3), C3-C4 1.494(3); O3-Tm1-04 74.78(6), C1-O2-Tm2 163.1(2), C2-O3-Tm1 112.88(13), C3-O4-Tm1 109.86(14). 
The bond distances within the oxygen heterocycle are consistent with a conjugated system and delocalization of one negative charge over $\mathrm{O} 2$ and $\mathrm{O} 4$, similar to the case in $\beta$-diketonate ligands. As a result, the C1-C2 and C2-C3 bond distances are almost identical (1.397(3) and 1.396(3) $\AA$, respectively), as are the $\mathrm{O} 2-\mathrm{C} 1$ and $\mathrm{O} 4-\mathrm{C} 3$ bond distances $(1.280(3)$ and $1.290(3) \AA$, respectively). In contrast, the unconjugated $\mathrm{O} 3-\mathrm{C} 2$ bond is longer with a distance of $1.339(3) \AA$. The Tm-O bond distances are lying in the range $2.200(2)-2.333(2) \AA$. The paramagnetic ${ }^{1} \mathrm{H}$ NMR spectrum of 7 features a complex baseline over the temperature range $20-80^{\circ} \mathrm{C}$ (see Figure S15), which results from the low symmetry of the complex in solution. In the IR spectrum, the coordinated $\beta$-diketonate group gives rise to an intense absorption band at $1639 \mathrm{~cm}^{-1}$.

Interestingly, reaction with $\mathrm{Me}_{3} \mathrm{SiOTf}$ did not lead to decoordination of the ethynediolate ligand, contrary to the reactivity observed by Liddle and co-workers upon treatment of a related tris-amido U(IV) ethynediolate complex with a strong silyl electrophile (see Scheme 5). ${ }^{17 i}$ In this previous study, the reaction with $\mathrm{Me}_{3} \mathrm{Sil}$ led to the silylation of the hydroxy groups and liberation of the ethynediolate fragment, which subsequently dimerized and rearranged into a spectroscopically identified furanone product. Indeed, acetylene diether compounds have been found to be stable at room temperature only in the presence of bulky substituents, ${ }^{38}$ or $\eta^{2}$-coordinated to transition metals. ${ }^{16 \mathrm{~b}}$ The $\mathrm{X}$-ray authenticated complex 7 unambiguously shows the formation of a similar furanone moiety in which the two trimethylsilyl groups are attached at the $\mathrm{C} 4$ position of the heterocycle rather than the $\mathrm{O} 3$ and $\mathrm{O} 4$ oxygen atoms, the latter remaining coordinated to metal center. The exploration of other functionalization agents to allow the liberation of the ethynediolate moiety is currently in progress.

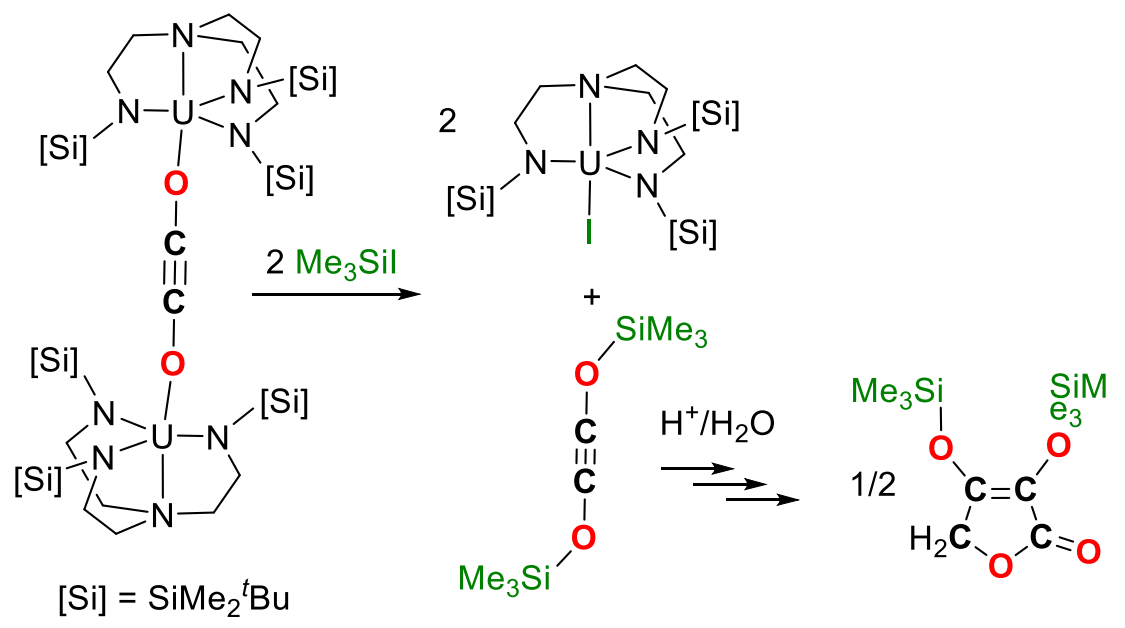

Scheme 5. Reported reactivity of a tris-amide U(IV) ethynediolate complex with $\mathrm{Me}_{3} \mathrm{Sil}^{17 \mathrm{i}}$

We next evaluated the reactivity of 2 towards $\mathrm{CO}_{2}$ (Scheme 4). The addition of $\mathrm{CO}_{2}$ ( 1.3 bar, excess) to a solution of $\mathbf{2}$ in toluene led to an immediate reaction at room temperature. After work-up, red crystals of 9 suitable for XRD studies were obtained in good yield (71\%) from a concentrated pentane solution. The molecular structure of the complex is depicted in Figure 9 and reveals the formation of an unexpected 
product in which $\mathrm{C}-\mathrm{H}$ activation at the para position of the toluene solvent occurred, yielding an unprecedented polyoxygenated ligand framework. In the resulting tetranuclear Tm(III) complex, only six $\mathrm{Cp}^{\mathrm{ttt}}$ ligands are present, suggesting that two $\mathrm{Cp}^{\text {ttt }}$ ligands have been released in their protonated form. The formation of $\mathrm{HCp}^{\text {ttt }}$ was indeed confirmed by ${ }^{1} \mathrm{H}$ NMR analysis of the volatiles of the reaction (see details in the Supporting Information and Figure S21). The thulium metal centers are hold together via two isomeric bridging $\left\{\mu_{3}-\mathrm{C}_{7} \mathrm{H}_{7}\left(\mathrm{C}_{4} \mathrm{O}_{6}\right)\right\}^{2-}$ fragments. Fragment $A$ (see Scheme 4 ) is best described by a $\mu_{3}-$ $\kappa^{2}\left(O^{1}, O^{3}\right): \kappa^{2}\left(O^{2}, O^{5}\right): \kappa^{3}\left(O^{4}, O^{5}, O^{6}\right)-\mathrm{C}_{7} \mathrm{H}_{7}\left(\mathrm{C}_{4} \mathrm{O}_{6}\right)$ ligand based on a 2-hydroxy-2-( $p$-toluoyl)malonate framework while fragment $\mathrm{B}$ corresponds to a $\mu_{3}-\kappa^{2}\left(O^{7}, O^{8}\right): \kappa^{2}\left(O^{7}, O^{10}\right): \kappa^{2}\left(O^{11}, O^{12}\right)-\mathrm{C}_{7} \mathrm{H}_{7}\left(\mathrm{C}_{4} \mathrm{O}_{6}\right)$ ligand derived from 2(carboxyoxy)-3-hydroxy-3-( $p$-tolyl)acrylic acid (a simplified view in which the $\mathrm{Cp}^{\text {ttt }}$ ligands have been omitted is depicted in Figure S46). Both Tm1 and Tm4 are coordinated by two $\eta^{5}-\mathrm{Cp}^{\text {ttt }}$ ligands and two oxygen atoms with Tm-O bond distances in the range 2.195(3)- 2.273(3) A. In contrast, Tm2 and Tm3 feature half-sandwich arrangements, both surrounded by one $\eta^{5}-\mathrm{Cp}{ }^{\text {ttt }}$ ligand along with four and five oxygen donors, respectively. The corresponding $\mathrm{Tm}-\mathrm{O}$ bond distances are spanning a much larger range (2.156(3)-2.643(3) $\AA$ ), as the result of the different types of oxygen donor functions, namely alkoxide, ketone, carboxylate and carbonate groups. The tetrasubstituted carbon $\mathrm{C} 2$ in fragment $\mathrm{A}$ features $\mathrm{C}-\mathrm{C}$ bond distances of 1.550(5)-1.567(5) Å corresponding to single bonds, whereas the C13-C14 and C14-C15 bond distances in fragment $B$ of $1.426(6)$ and $1.384(6) \AA$, respectively, are more consistent with a delocalized double bond within the 3-hydroxyacrylate moiety. Accordingly, the sum of the bonding angles around $\mathrm{C} 14$ and $\mathrm{C} 15$ of $360.0^{\circ}$ is indicative of $\mathrm{sp}^{2}$ hybridization.

The ${ }^{1} \mathrm{H}$ NMR spectrum of 9 in toluene- $d_{8}$ (Figure S18) shows a very complex pattern with several paramagnetically shifted resonances in the range $\delta-360$ to $+300 \mathrm{ppm}$, as a result of the $C_{1}$ symmetric nature of 9 . Despite the complexity of the spectrum, the signals corresponding to the $p$-tolyl fragments could be successfully assigned by comparison with the spectrum of the partly deuterated $9-^{2} \mathbf{H}$ (see Figures S19-S20), the latter prepared using the same procedure but in toluene- $d_{8}$ instead of protio-toluene. The IR spectrum of 9 shows a very intense absorption band at $1638 \mathrm{~cm}^{-1}$, consistent with a coordinated ketone group, along with strong absorption bands at 1585 and $1552 \mathrm{~cm}^{-1}$, which can be assigned to the carboxylate groups and/or delocalized $\mathrm{C}=\mathrm{C}$ bond in the newly formed ligand. 


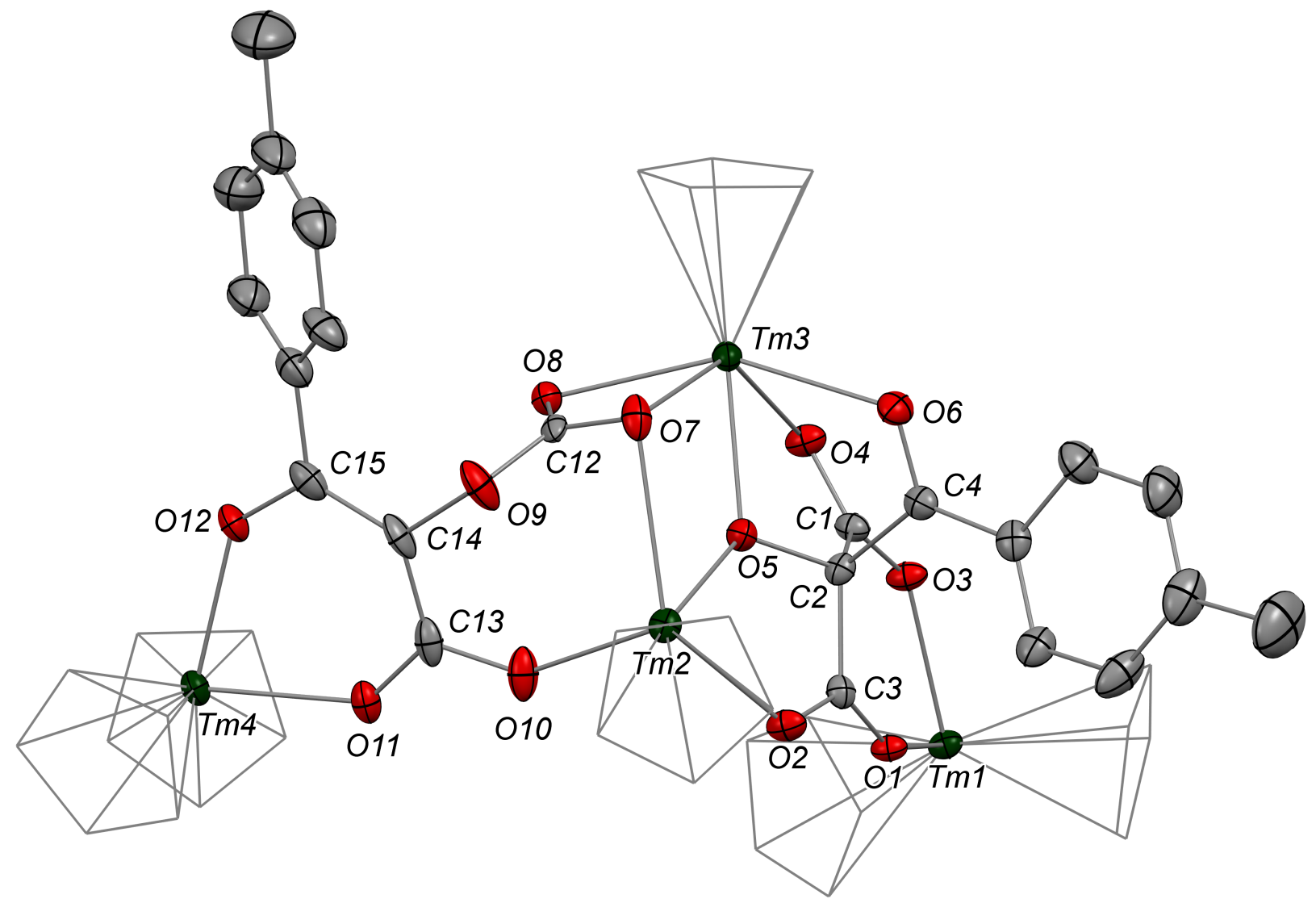

Figure 9. Molecular structure of $\mathbf{9}$ in the solid state with thermal ellipsoids at the $40 \%$ probability level (except for the $\mathrm{Cp}$ groups depicted in wireframe). $\mathrm{H}$ atoms, ${ }^{t} \mathrm{Bu}$ groups and non-coordinating solvent molecules have been omitted for clarity. Selected bond distances (Å): Tm1-01 2.273(3), Tm1-03 2.242(3), Tm2-02 2.266(3), Tm2-05 2.263(3), Tm2-07 2.643(3), Tm2-010 2.156(3), Tm3-04 2.261(3), Tm3-05 2.294(3), Tm3-06 2.386(3), Tm3-07 2.428(3), Tm3-08 2.333(3), Tm4-011 2.234(3), Tm4-012 2.195(3), O1-C3 1.244(4), O2-C3 1.252(5), O3-C1 1.248(4), O4-C1 1.259(4), O5-C2 1.402(4), O6-C4 1.235(5), O7C12 1.271(4), O8-C12 1.231(5), O9-C12 1.338(5), O9-C14 1.428(5), O10-C13 1.291(5), O11-C13 1.260(5), O12-C15 1.300(5), C1-C2 1.565(5), C2-C3 1.550(5), C2-C4 1.567(5), C13-C14 1.426(6), C14-C15 1.384(6).

A detailed study of the elementary steps leading to the formation of 9 is outside the scope of this publication and will be disclosed in due course. A possible simplified mechanism to account for the formation of the two polyoxygenated fragments is depicted in Scheme 6 . In both cases, it would begin with an electrophilic aromatic substitution on the toluene solvent induced by the interaction of the ethynediolate complex 2 with $\mathrm{CO}_{2}$. The acidic proton in the Wheland intermediate is trapped by one $\mathrm{Cp}^{\mathrm{ttt}}$ ligand, resulting in the release of $\mathrm{HCp}^{\text {ttt }}$, which was observed spectroscopically. This first step could therefore be seen as a Friedel-Crafts-type reaction leading to the functionalization of toluene and formation of a deprotonated form of 2,3-dihydroxy-3-( $p$-tolyl)acrylate. This polyoxygenated intermediate further reacts with one more equivalent of $\mathrm{CO}_{2}$ either at the nucleophilic carbon atom or at the nonconjugated anionic oxygen atom, yielding fragments $A$ or $B$, respectively. 


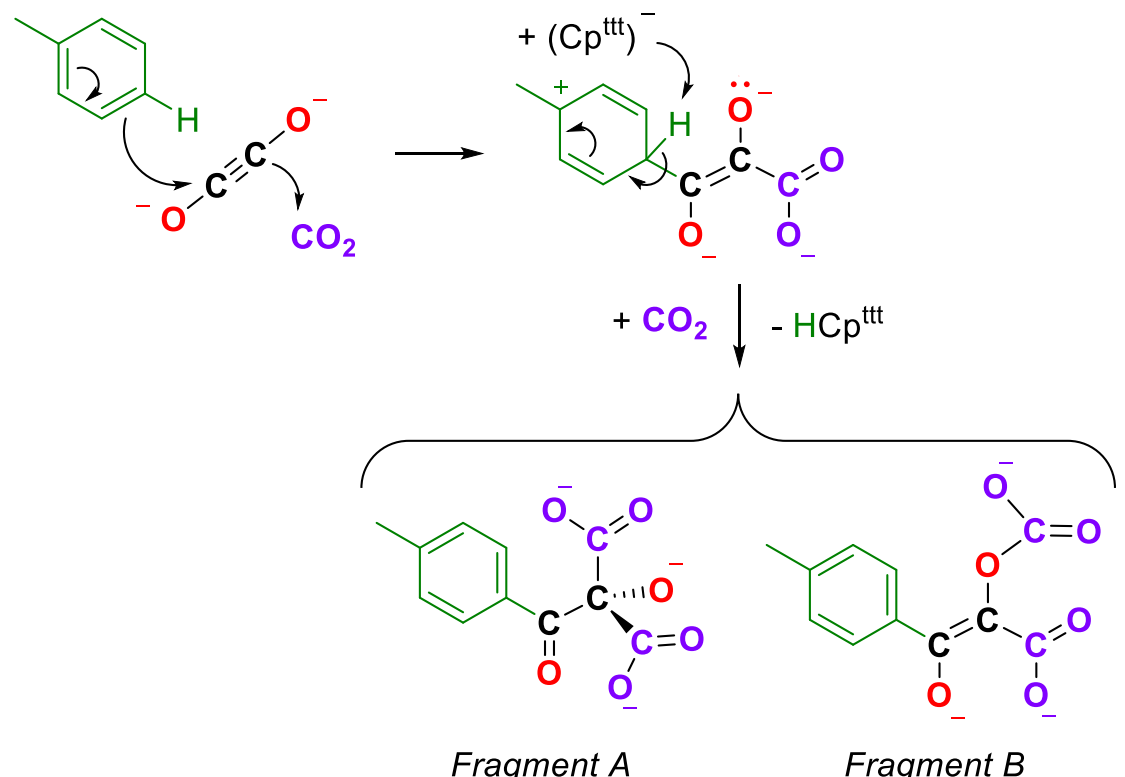

Scheme 6. Suggested mechanism in the formation of 9 leading to the formation of fragments A and B.

It should be noted that this reaction proceeds smoothly at room temperature and in a reproducible manner. It contrasts with the thermolysis reactivity of some uranium(IV) ethynediolate complexes that were found to react at elevated temperature through ligand degradation or intramolecular $\mathrm{C}-\mathrm{H}$ activation at the ligand backbone, resulting in the formation of ethenediolate-type complexes. ${ }^{17 \mathrm{~h}, 17 \mathrm{i}}$ The observed C$\mathrm{H}$ activation of toluene in $\mathbf{9}$ is somehow reminiscent of the $\mathrm{C}-\mathrm{H}$ activation at the coordinated 4dimethylaminopyridine (DMAP) ligand upon addition of $\mathrm{CO}$ to an activated $\mathrm{Mg}(\mathrm{l})$ dimer complex (see Figure 1). ${ }^{15 g}$ In this case, DFT calculations suggested that the $\mathrm{C}-\mathrm{H}$ activation is induced by a "zig-zag" $\left\{\mathrm{C}_{2} \mathrm{O}_{2}\right\}^{2-}$ intermediate similar to iso2 (Figure 5). The major difference in the case of 2 lies in its lack of reactivity in toluene in the absence of $\mathrm{CO}_{2}$, even at elevated temperatures (up to $100^{\circ} \mathrm{C}$ ). Only upon addition of $\mathrm{CO}_{2}$ is a highly reactive system formed that allows intermolecular $\mathrm{C}-\mathrm{H}$ activation on toluene.

\section{Conclusion}

In conclusion, the divalent thulium complex $\left[\mathrm{Tm}\left(\mathrm{Cp}^{\mathrm{ttt}}\right)_{2}\right]$ exhibits a rich reactivity towards $\mathrm{CO}$ and $\mathrm{CO}_{2}$ allowing the selective formation of carbonate $\left(C_{1}\right)$, ethynediolate $\left(C_{2}\right)$ and ketenecarboxylate $\left(C_{3}\right)$ complexes. The reactivity of the $\mathrm{CO}$ dimerization product $\mathbf{2}$ with external $\mathrm{CO}$ at room temperature is remarkable and proves the intermediacy of $\mathbf{2}$ in the formation of the ketenecarboxylate complex $\mathbf{3}$, which was also supported by DFT calculations. The reactivity of $\mathbf{2}$ and $\mathbf{3}$ was systematically investigated towards electrophiles leading to the following observations: (a) while $\mathbf{3}$ features an expected nucleophilic reactivity towards $\mathrm{CO}_{2}$, the addition of methyl iodide yields a $\mathrm{C}_{7}$ allene-tricarboxylate complex in which the $\mathrm{C}_{6} \mathrm{O}_{6}$ core is exclusively built from CO molecules; (b) the ethynediolate complex $\mathbf{2}$ shows unexpected reactivity towards $\mathrm{CO}_{2}$ and silylating agents. In the case of $\mathrm{CO}_{2}$, a highly reactive species is formed, which is able to induce an intermolecular $\mathrm{C}-\mathrm{H}$ activation on the solvent. This novel reactivity opens new ways for the formation of multicarbon oxygenates by small molecule activation and the functionalization of $\mathrm{CO}$ and $\mathrm{CO}_{2}$ 
to value-added chemicals. The exploration of new procedures to enable decoordination of the oxygenated products and further catalytic applications are currently in progress in our laboratory.

\section{Associated Content}

Supporting Information: Full experimental details, ${ }^{1} \mathrm{H}$ NMR spectra, IR spectra, X-ray crystallographic details and DFT calculations.

X-ray crystallographic data for 1-7 and $\mathbf{9}$ are available from the Cambridge Crystallographic Data Centre (CCDC 2118417-2118424) free of charge via www.ccdc.cam.ac.uk/data request/cif, or by emailing data request@ccdc.cam.ac.uk, or by contacting The Cambridge Crystallographic Data Centre, 12 Union Road, Cambridge CB2 1EZ, UK; fax: +44 1223336033.

\section{Author Information Notes}

The authors declare no competing financial interest.

ORCID ID:

- for TS: orcid.org/0000-0002-0184-303X

- $\quad$ for LM: orcid.org/0000-0003-2653-8557

- $\quad$ for GN: orcid.org/0000-0003-0599-1176

\section{Acknowledgments}

This project has received funding from the European Research Council (ERC) under the European Union' Horizon H2020 research program (grant agreement No. 716314). CNRS and Ecole Polytechnique are thanked for funding. LM is a senior member of the Institut Universitaire de France. CalMip is acknowledged for a generous grant of computing time.

\section{References}

(1) Activation of Small Molecules: Organometallic and Bioinorganic Perspectives; Tolman, W. B., Ed.; WileyVCH Verlag: Weinheim, 2006, pp. 1-363.

(2) (a) Klier, K. In Advances in Catalysis; Eley, D. D., Pines, H., Weisz, P. B., Eds.; Academic Press: 1982; Vol. 31, p. 243-313; (b) Jones, P. M.; May, J. A.; Reitz, J. B.; Solomon, E. I. Photoelectron Spectroscopic and Electronic Structure Studies of $\mathrm{CH}_{2} \mathrm{O}$ Bonding and Reactivity on $\mathrm{ZnO}$ Surfaces: Steps in the Methanol Synthesis Reaction. Inorg. Chem. 2004, 43, 3349-3370.

(3) Jones, J. H. The Cativa ${ }^{\mathrm{TM}}$ Process for the Manufacture of Acetic Acid. Platinum Met. Rev. 2000, 44, 94105.

(4) (a) Fischer, F.; Tropsch, H. The Synthesis of Petroleum at Atmospheric Pressures from Gasification Products of Coal. Brenn. Chem. 1926, 7, 97-104; (b) Masters, C. In Advances in Organometallic Chemistry; Stone, F. G. A., West, R., Eds.; Academic Press: 1979; Vol. 17, p. 61-103; (c) West, N. M.; Miller, A. J. M.; Labinger, J. A.; Bercaw, J. E. Homogeneous syngas conversion. Coord. Chem. Rev. 2011, 255, 881-898; (d) de Klerk, A. In Kirk-Othmer Encyclopedia of Chemical Technology; Wiley-VCH: Weinheim: 2013, p. 1-20. (5) Kalescky, R.; Kraka, E.; Cremer, D. Identification of the Strongest Bonds in Chemistry. J. Phys. Chem. A 2013, 117, 8981-8995. 
(6) (a) Rofer-DePoorter, C. K. A comprehensive mechanism for the Fischer-Tropsch synthesis. Chem. Rev. 1981, 81, 447-474; (b) Khodakov, A. Y.; Chu, W.; Fongarland, P. Advances in the Development of Novel Cobalt Fischer-Tropsch Catalysts for Synthesis of Long-Chain Hydrocarbons and Clean Fuels. Chem. Rev. 2007, 107, 1692-1744.

(7) (a) Wolczanski, P. T.; Bercaw, J. E. Mechanisms of carbon monoxide reduction with zirconium hydrides. Acc. Chem. Res. 1980, 13, 121-127; (b) Herrmann, W. A. Organometallic Aspects of the Fischer-Tropsch Synthesis. Angew. Chem., Int. Ed. Engl. 1982, 21, 117-130; (c) Whyman, R.; Wright, A. P.; Iggo, J. A.; Heaton, B. T. Carbon monoxide activation in homogeneously catalysed reactions: the nature and roles of catalytic promoters. J. Chem. Soc., Dalton Trans. 2002, 771-777; (d) Buss, J. A.; Agapie, T. Four-electron deoxygenative reductive coupling of carbon monoxide at a single metal site. Nature 2016, 529, 72-75; (e) Labinger, J. A. Approaches to homogeneously catalyzed $\mathrm{CO}$ hydrogenation: A personal retrospective. J. Organomet. Chem. 2017, 847, 4-12; (f) Buss, J. A.; Bailey, G. A.; Oppenheim, J.; VanderVelde, D. G.; Goddard, W. A.; Agapie, T. CO Coupling Chemistry of a Terminal Mo Carbide: Sequential Addition of Proton, Hydride, and CO Releases Ethenone. J. Am. Chem. Soc. 2019, 141, 15664-15674; (g) Ohata, J.; Teramoto, A.; Fujita, H.; Takemoto, S.; Matsuzaka, H. Linear Hydrocarbon Chain Growth from a Molecular Diruthenium Carbide Platform. J. Am. Chem. Soc. 2021, 143, 16105-16112.

(8) (a) Phanopoulos, A.; Pal, S.; Kawakami, T.; Nozaki, K. Heavy-Metal-Free Fischer-Tropsch Type Reaction: Sequential Homologation of Alkylborane Using a Combination of $\mathrm{CO}$ and Hydrides as Methylene Source. J. Am. Chem. Soc. 2020, 142, 14064-14068; (b) Xu, M.; Qu, Z.-w.; Grimme, S.; Stephan, D. W. Lithium Dicyclohexylamide in Transition-Metal-Free Fischer-Tropsch Chemistry. J. Am. Chem. Soc. 2021, 143, 634638.

(9) (a) Evans, W. J.; Wayda, A. L.; Hunter, W. E.; Atwood, J. L. Organolanthanoid activation of carbon monoxide: single and multiple insertion of $\mathrm{CO}$ into $t$-butyl lanthanoid bonds; X-ray crystallographic identification of a new bonding mode for a bridging enedione diolate ligand formed by formal coupling of four CO molecules. J. Chem. Soc., Chem. Commun. 1981, 706-708; (b) Marks, T. J. Actinide Organometallic Chemistry. Science 1982, 217, 989-997; (c) Moloy, K. G.; Marks, T. J. Carbon monoxide activation by organoactinides. A comparative synthetic, thermodynamic, kinetic, and mechanistic investigation of migratory carbon monoxide insertion into actinide-carbon and actinide-hydrogen bonds to yield $\eta^{2}$-acyls and $\eta^{2}$-formyls. J. Am. Chem. Soc. 1984, 106, 7051-7064.

(10) Sharpe, H. R.; Geer, A. M.; Taylor, L. J.; Gridley, B. M.; Blundell, T. J.; Blake, A. J.; Davies, E. S.; Lewis, W.; McMaster, J.; Robinson, D.; Kays, D. L. Selective reduction and homologation of carbon monoxide by organometallic iron complexes. Nat. Commun. 2018, 9, 3757.

(11) (a) Evans, W. J.; Grate, J. W.; Doedens, R. J. Organolanthanide and organoyttrium hydride chemistry. 7. Reaction of the samarium-hydrogen bond in the organosamarium hydride $\left[\left(\mathrm{C}_{5} \mathrm{Me}_{5}\right)_{2} \mathrm{SmH}\right]_{2}$ with carbon monoxide: formation, isomerization, and $\mathrm{x}$-ray crystallographic characterization of the samarium complexes cis- and trans- $\left\{\left(\mathrm{C}_{5} \mathrm{Me}_{5}\right)_{2}\left[\left(\mathrm{C}_{6} \mathrm{H}_{5}\right)_{3} \mathrm{PO}\right] \mathrm{Sm}\right\}_{2}(\mu-\mathrm{OCH}=\mathrm{CHO})$. J. Am. Chem. Soc. 1985, 107, 1671-1679; (b) Cummins, C. C.; Van Duyne, G. D.; Schaller, C. P.; Wolczanski, P. T. Carbonylation of zirconium complex [tert-Bu $\left.\mathrm{Bu}_{3} \mathrm{SiNH}\right]_{3} \mathrm{ZrH}$ and X-ray structural study of [tert-Bu $3 \mathrm{SiNH}_{3} \mathrm{ZrCH}_{3}$. Organometallics 1991, 10, 164-170; (c) Werkema, E. L.; Maron, L.; Eisenstein, O.; Andersen, R. A. Reactions of Monomeric [1,2,4$\left.\left(\mathrm{Me}_{3} \mathrm{C}\right)_{3} \mathrm{C}_{5} \mathrm{H}_{2}\right]_{2} \mathrm{CeH}$ and $\mathrm{CO}$ with or without $\mathrm{H}_{2}$ : An Experimental and Computational Study. J. Am. Chem. Soc. 2007, 129, 2529-2541; (d) Lalrempuia, R.; Kefalidis, C. E.; Bonyhady, S. J.; Schwarze, B.; Maron, L.; Stasch, A.; Jones, C. Activation of CO by Hydrogenated Magnesium(I) Dimers: Sterically Controlled Formation of Ethenediolate and Cyclopropanetriolate Complexes. J. Am. Chem. Soc. 2015, 137, 8944-8947; (e) Anker, M. D.; Kefalidis, C. E.; Yang, Y.; Fang, J.; Hill, M. S.; Mahon, M. F.; Maron, L. Alkaline EarthCentered CO Homologation, Reduction, and Amine Carbonylation. J. Am. Chem. Soc. 2017, 139, 1003610054; (f) Hu, S.; Shima, T.; Hou, Z. Hydrodeoxygenative Cyclotetramerization of Carbon Monoxide by a Trinuclear Titanium Polyhydride Complex. J. Am. Chem. Soc. 2020, 142, 19889-19894.

(12) Heilmann, A.; Hicks, J.; Vasko, P.; Goicoechea, J. M.; Aldridge, S. Carbon Monoxide Activation by a Molecular Aluminium Imide: C-O Bond Cleavage and C-C Bond Formation. Angew. Chem. Int. Ed. 2020, 59, 4897-4901.

(13) Wang, B.; Luo, G.; Nishiura, M.; Luo, Y.; Hou, Z. Cooperative Trimerization of Carbon Monoxide by Lithium and Samarium Boryls. J. Am. Chem. Soc. 2017, 139, 16967-16973.

(14) (a) Kong, R. Y.; Crimmin, M. R. Cooperative strategies for CO homologation. Dalton Trans. 2020, 49, 16587-16597; (b) Rosenthal, U. Carbon Monoxide Coupling Reactions: A New Concept for the Formation 
of Hexahydroxybenzene. Chem.-Eur. J. 2020, 26, 14507-14511; (c) Fujimori, S.; Inoue, S. Main group carbonyl complexes. Commun. Chem. 2020, 3, 175.

(15) (a) Braunschweig, H.; Dellermann, T.; Dewhurst, R. D.; Ewing, W. C.; Hammond, K.; Jimenez-Halla, J. O. C.; Kramer, T.; Krummenacher, I.; Mies, J.; Phukan, A. K.; Vargas, A. Metal-free binding and coupling of carbon monoxide at a boron-boron triple bond. Nat. Chem. 2013, 5, 1025-1028; (b) Majumdar, M.; Omlor, I.; Yildiz, C. B.; Azizoglu, A.; Huch, V.; Scheschkewitz, D. Reductive Cleavage of Carbon Monoxide by a Disilenide. Angew. Chem. Int. Ed. 2015, 54, 8746-8750; (c) Kong, R. Y.; Crimmin, M. R. Carbon Chain Growth by Sequential Reactions of $\mathrm{CO}$ and $\mathrm{CO}_{2}$ with $\left[\mathrm{W}(\mathrm{CO})_{6}\right]$ and an Aluminum(I) Reductant. J. Am. Chem. Soc. 2018, 140, 13614-13617; (d) Wang, Y.; Kostenko, A.; Hadlington, T. J.; Luecke, M.-P.; Yao, S.; Driess, M. Silicon-Mediated Selective Homo- and Heterocoupling of Carbon Monoxide. J. Am. Chem. Soc. 2019, 141, 626-634; (e) Yuvaraj, K.; Douair, I.; Paparo, A.; Maron, L.; Jones, C. Reductive Trimerization of CO to the Deltate Dianion Using Activated Magnesium(I) Compounds. J. Am. Chem. Soc. 2019, 141, 8764-8768; (f) Protchenko, A. V.; Vasko, P.; Do, D. C. H.; Hicks, J.; Fuentes, M. Á.; Jones, C.; Aldridge, S. Reduction of Carbon Oxides by an Acyclic Silylene: Reductive Coupling of CO. Angew. Chem. Int. Ed. 2019, 58, 18081812; (g) Yuvaraj, K.; Douair, I.; Jones, D. D. L.; Maron, L.; Jones, C. Sterically controlled reductive oligomerisations of $\mathrm{CO}$ by activated magnesium(I) compounds: deltate vs. ethenediolate formation. Chem. Sci. 2020, 11, 3516-3522; (h) Xiong, Y.; Yao, S.; Szilvási, T.; Ruzicka, A.; Driess, M. Homocoupling of CO and isocyanide mediated by a C, $C^{\prime}$-bis(silylenyl)-substituted ortho-carborane. Chem. Commun. 2020, 56, 747750; (i) Paparo, A.; Yuvaraj, K.; Matthews, A. J. R.; Douair, I.; Maron, L.; Jones, C. Reductive Hexamerization of CO Involving Cooperativity Between Magnesium(I) Reductants and [Mo(CO) 6 ]: Synthesis of Well-Defined Magnesium Benzenehexolate Complexes**. Angew. Chem. Int. Ed. 2021, 60, 630-634; (j) Liu, H.-Y.; Schwamm, R. J.; Neale, S. E.; Hill, M. S.; McMullin, C. L.; Mahon, M. F. Reductive Dimerization of CO by a Na/Mg(I) Diamide. J. Am. Chem. Soc. 2021, ASAP. DOI: 10.1021/jacs.1c09467; (k) Kong, R. Y.; Batuecas, M.; Crimmin, M. R. Reactions of Aluminium(I) with Transition Metal Carbonyls: Scope, Mechanism and Selectivity of CO Homologation. Chem. Sci. 2021, DOI: 10.1039/D1SC04940B.

(16) (a) Bianconi, P. A.; Williams, I. D.; Engeler, M. P.; Lippard, S. J. Reductive coupling of two carbon monoxide ligands to form a coordinated alkyne. J. Am. Chem. Soc. 1986, 108, 311-313; (b) Carnahan, E. M.; Protasiewicz, J. D.; Lippard, S. J. The 15 years of reductive coupling: what have we learned? Acc. Chem. Res. 1993, 26, 90-97; (c) Wayland, B. B.; Sherry, A. E.; Coffin, V. L. Selective reductive coupling of carbon monoxide. J. Chem. Soc., Chem. Commun. 1989, 662-663; (d) Watanabe, T.; Ishida, Y.; Matsuo, T.; Kawaguchi, H. Reductive Coupling of Six Carbon Monoxides by a Ditantalum Hydride Complex. J. Am. Chem. Soc. 2009, 131, 3474-3475; (e) Fang, M.; Farnaby, J. H.; Ziller, J. W.; Bates, J. E.; Furche, F.; Evans, W. J. Isolation of $(\mathrm{CO})^{1-}$ and $\left(\mathrm{CO}_{2}\right)^{1-}$ Radical Complexes of Rare Earths via $\operatorname{Ln}\left(\mathrm{NR}_{2}\right)_{3} / \mathrm{K}$ Reduction and $\left[\mathrm{K}_{2}(18-\right.$ crown-6) $\left.{ }_{2}\right]^{2+}$ Oligomerization. J. Am. Chem. Soc. 2012, 134, 6064-6067.

(17) (a) Evans, W. J.; Grate, J. W.; Hughes, L. A.; Zhang, H.; Atwood, J. L. Reductive homologation of carbon monoxide to a ketenecarboxylate by a low-valent organolanthanide complex: synthesis and $\mathrm{x}$-ray crystal structure of $\left[\left(\mathrm{C}_{5} \mathrm{Me}_{5}\right)_{4} \mathrm{Sm}_{2}\left(\mathrm{O}_{2} \mathrm{CCCO}\right)(\mathrm{THF})\right]_{2}$. J. Am. Chem. Soc. 1985, 107, 3728-3730; (b) Evans, W. J.; Lee, D. S.; Ziller, J. W.; Kaltsoyannis, N. Trivalent $\left[\left(\mathrm{C}_{5} \mathrm{Me}_{5}\right)_{2}(\mathrm{THF}) \mathrm{Ln}_{2}\left(\mu-\eta^{2}: \eta^{2}-\mathrm{N}_{2}\right)\right.$ Complexes as Reducing Agents Including the Reductive Homologation of $\mathrm{CO}$ to a Ketene Carboxylate, $\left(\mu-\eta^{4}-\mathrm{O}_{2} \mathrm{CCCO}\right)^{2-}$. J. Am. Chem. Soc. 2006, 128, 14176-14184; (c) Wayland, B.; Fu, X. Building Molecules with Carbon Monoxide Reductive Coupling. Science 2006, 311, 790-791; (d) Summerscales, O. T.; Cloke, F. G. N.; Hitchcock, P. B.; Green, J. C.; Hazari, N. Reductive Cyclotrimerization of Carbon Monoxide to the Deltate Dianion by an Organometallic Uranium Complex. Science 2006, 311, 829-831; (e) Summerscales, O. T.; Cloke, F. G. N.; Hitchcock, P. B.; Green, J. C.; Hazari, N. Reductive Cyclotetramerization of CO to Squarate by a U(III) Complex: The X-ray Crystal Structure of $\left[\left(\mathrm{U}\left(\eta-\mathrm{C}_{8} \mathrm{H}_{6}\left\{\mathrm{Si}^{i} \mathrm{Pr}_{3}-1,4\right\}_{2}\right)\left(\eta-\mathrm{C}_{5} \mathrm{Me}_{4} \mathrm{H}\right)\right]_{2}\left(\mu-\eta^{2}: \eta^{2}-\mathrm{C}_{4} \mathrm{O}_{4}\right)\right.$. J. Am. Chem. Soc. 2006, 128, 9602-9603; (f) Frey, A. S.; Cloke, F. G. N.; Hitchcock, P. B.; Day, I. J.; Green, J. C.; Aitken, G. Mechanistic Studies on the Reductive Cyclooligomerisation of $\mathrm{CO}$ by U(III) Mixed Sandwich Complexes; the Molecular Structure of $\left[\left(U\left(\eta-\mathrm{C}_{8} \mathrm{H}_{6}\left\{\mathrm{Si}^{i} \mathrm{Pr}_{3}-1,4\right\}_{2}\right)\left(\eta-\mathrm{Cp}{ }^{*}\right)\right]_{2}\left(\mu-\eta^{1}: \eta^{1}-\mathrm{C}_{2} \mathrm{O}_{2}\right)\right.$. J. Am. Chem. Soc. 2008, 130, 1381613817; (g) Mansell, S. M.; Kaltsoyannis, N.; Arnold, P. L. Small Molecule Activation by Uranium Tris(aryloxides): Experimental and Computational Studies of Binding of $\mathrm{N}_{2}$, Coupling of $\mathrm{CO}$, and Deoxygenation Insertion of $\mathrm{CO}_{2}$ under Ambient Conditions. J. Am. Chem. Soc. 2011, 133, 9036-9051; (h) Arnold, P. L.; Turner, Z. R.; Bellabarba, R. M.; Tooze, R. P. Carbon monoxide coupling and functionalisation at a simple uranium coordination complex. Chem. Sci. 2011, 2, 77-79; (i) Gardner, B. M.; Stewart, J. C.; Davis, A. L.; McMaster, J.; Lewis, W.; Blake, A. J.; Liddle, S. T. Homologation and functionalization of carbon 
monoxide by a recyclable uranium complex. Proc. Natl. Acad. Sci. U. S. A. 2012, 109, 9265-9270; (j) Tsoureas, N.; Summerscales, O. T.; Cloke, F. G. N.; Roe, S. M. Steric Effects in the Reductive Coupling of CO by Mixed-Sandwich Uranium(III) Complexes. Organometallics 2013, 32, 1353-1362; (k) Yadav, R.; Simler, T.; Gamer, M. T.; Köppe, R.; Roesky, P. W. Rhenium is different: $\mathrm{CO}$ tetramerization induced by a divalent lanthanide complex in rhenium carbonyls. Chem. Commun. 2019, 55, 5765-5768; (I) Ryan, A. J.; Ziller, J. W.; Evans, W. J. The importance of the counter-cation in reductive rare-earth metal chemistry: 18-crown6 instead of 2,2,2-cryptand allows isolation of $\left[\mathrm{Y}^{\prime \prime}\left(\mathrm{NR}_{2}\right)_{3}\right]^{1-}$ and ynediolate and enediolate complexes from CO reactions. Chem. Sci. 2020, 11, 2006-2014.

(18) (a) Aitken, G.; Hazari, N.; Frey, A. S. P.; Cloke, F. G. N.; Summerscales, O.; Green, J. C. Reductive coupling of carbon monoxide by U(III) complexes-a computational study. Dalton Trans. 2011, 40, 1108011088; (b) McKay, D.; Frey, A. S. P.; Green, J. C.; Cloke, F. G. N.; Maron, L. Computational insight into the reductive oligomerisation of $\mathrm{CO}$ at uranium(III) mixed-sandwich complexes. Chem. Commun. 2012, 48, 4118-4120.

(19) Nief, F. Non-classical divalent lanthanide complexes. Dalton Trans. 2010, 39, 6589-6598.

(20) (a) Xémard, M.; Goudy, V.; Braun, A.; Tricoire, M.; Cordier, M.; Ricard, L.; Castro, L.; Louyriac, E.; Kefalidis, C. E.; Clavaguéra, C.; Maron, L.; Nocton, G. Reductive Disproportionation of $\mathrm{CO}_{2}$ with Bulky Divalent Samarium Complexes. Organometallics 2017, 36, 4660-4668; (b) Goudy, V.; Jaoul, A.; Cordier, M.; Clavaguéra, C.; Nocton, G. Tuning the Stability of Pd(IV) Intermediates Using a Redox Non-innocent Ligand Combined with an Organolanthanide Fragment. J. Am. Chem. Soc. 2017, 139, 10633-10636; (c) Xémard, M.; Cordier, M.; Louyriac, E.; Maron, L.; Clavaguéra, C.; Nocton, G. Small molecule activation with divalent samarium triflate: a synergistic effort to cleave $\mathrm{O}_{2}$. Dalton Trans. 2018, 47, 9226-9230; (d) Wang, D.; Moutet, J.; Tricoire, M.; Cordier, M.; Nocton, G. Reactive Heterobimetallic Complex Combining Divalent Ytterbium and Dimethyl Nickel Fragments. Inorganics 2019, 7, 58.

(21) (a) Jaroschik, F.; Nief, F.; Ricard, L. Synthesis of a new stable, neutral organothulium(II) complex by reduction of a thulium(III) precursor. Chem. Commun. 2006, 426-428; (b) Jaroschik, F.; Nief, F.; Le Goff, X.F.; Ricard, L. Synthesis and Reactivity of Organometallic Complexes of Divalent Thulium with Cyclopentadienyl and Phospholyl Ligands. Organometallics 2007, 26, 3552-3558.

(22) (a) Weber, F.; Schultz, M.; Sofield, C. D.; Andersen, R. A. Synthesis and Solid State Structures of Sterically Crowded d $\mathrm{d}^{0}$-Metallocenes of Magnesium, Calcium, Strontium, Barium, Samarium, and Ytterbium. Organometallics 2002, 21, 3139-3146; (b) Nocton, G.; Ricard, L. N-aromatic heterocycle adducts of bulky [1,2,4-( $\left.\left(\mathrm{Me}_{3} \mathrm{C}\right)_{3} \mathrm{C}_{5} \mathrm{H}_{2}\right]_{2} \mathrm{Sm}$ : synthesis, structure and solution analysis. Dalton Trans. 2014, 43, 4380-4387; (c) Sitzmann, H.; Dezember, T.; Schmitt, O.; Weber, F.; Wolmershäuser, G.; Ruck, M. Metallocenes of Samarium, Europium, and Ytterbium with the Especially Bulky Cyclopentadienyl Ligands $\mathrm{C}_{5} \mathrm{H}\left(\mathrm{CHMe}_{2}\right)_{4}$, $\mathrm{C}_{5} \mathrm{H}_{2}\left(\mathrm{CMe}_{3}\right)_{3}$, and $\mathrm{C}_{5}\left(\mathrm{CHMe}_{2}\right)_{5}$. Z. Anorg. Allg. Chem. 2000, 626, 2241-2244.

(23) (a) Shannon, R. Revised effective ionic radii and systematic studies of interatomic distances in halides and chalcogenides. Acta Crystallogr., Sect. A 1976, 32, 751-767; (b) Walter, M. D.; Wolmershäuser, G.; Sitzmann, H. Calcium, Strontium, Barium, and Ytterbium Complexes with Cyclooctatetraenyl or Cyclononatetraenyl Ligands' ${ }^{1}$. J. Am. Chem. Soc. 2005, 127, 17494-17503.

(24) (a) Bochkarev, M. N. Molecular compounds of "new" divalent lanthanides. Coord. Chem. Rev. 2004, 248, 835-851; (b) Moutet, J.; Schleinitz, J.; La Droitte, L.; Tricoire, M.; Pointillart, F.; Gendron, F.; Simler, T.; Clavaguéra, C.; Le Guennic, B.; Cador, O.; Nocton, G. Bis-Cyclooctatetraenyl Thulium(II): Highly Reducing Lanthanide Sandwich Single-Molecule Magnets. Angew. Chem. Int. Ed. 2021, 60, 6042-6046.

(25) Evans, W. J.; Ulibarri, T. A.; Ziller, J. W. Isolation and X-ray crystal structure of the first dinitrogen complex of an f-element metal, $\left[\left(\mathrm{C}_{5} \mathrm{Me}_{5}\right)_{2} \mathrm{Sm}\right]_{2} \mathrm{~N}_{2}$. J. Am. Chem. Soc. 1988, 110, 6877-6879.

(26) (a) Evans, W. J.; Allen, N. T.; Ziller, J. W. Facile Dinitrogen Reduction via Organometallic Tm(II) Chemistry. J. Am. Chem. Soc. 2001, 123, 7927-7928; (b) Fedushkin, Igor L.; Girgsdies, F.; Schumann, H.; Bochkarev, Mikhail N. Formation and Structure of Thulium(III) Cyclopentadienides as Products of Reactions Directed Towards the Synthesis of Thulium(II) Cyclopentadienides. Eur. J. Inorg. Chem. 2001, 2001, 24052410; (c) Evans, W. J.; Allen, N. T.; Ziller, J. W. Expanding Divalent Organolanthanide Chemistry: The First Organothulium(II) Complex and the In Situ Organodysprosium(II) Reduction of Dinitrogen. Angew. Chem. Int. Ed. 2002, 41, 359-361; (d) Nief, F.; Turcitu, D.; Ricard, L. Synthesis and structure of phospholyl- and arsolylthulium(II) complexes. Chem. Commun. 2002, 1646-1647; (e) Nief, F.; de Borms, B. T.; Ricard, L.; Carmichael, D. New Complexes of Divalent Thulium with Substituted Phospholyl and Cyclopentadienyl Ligands. Eur. J. Inorg. Chem. 2005, 2005, 637-643. 
(27) (a) Evans, W. J. Tutorial on the Role of Cyclopentadienyl Ligands in the Discovery of Molecular Complexes of the Rare-Earth and Actinide Metals in New Oxidation States. Organometallics 2016, 35, 3088-3100; (b) Trinh, M. T.; Wedal, J. C.; Evans, W. J. Evaluating electrochemical accessibility of $4 \mathrm{f}^{\mathrm{n}} 5 \mathrm{~d}^{1}$ and $4 \mathrm{f}^{\mathrm{n}+1} \mathrm{Ln}(\mathrm{II})$ ions in $\left(\mathrm{C}_{5} \mathrm{H}_{4} \mathrm{SiMe}_{3}\right)_{3} \mathrm{Ln}$ and $\left(\mathrm{C}_{5} \mathrm{Me}_{4} \mathrm{H}\right)_{3} \mathrm{Ln}$ complexes. Dalton Trans. 2021, 50, 14384-14389.

(28) Cotton, S. In Lanthanide and Actinide Chemistry; John Wiley \& Sons, Ltd.: Chichester (U.K.), 2006, p. 1-263.

(29) (a) Bowman, L. J.; Izod, K.; Clegg, W.; Harrington, R. W. Synthesis and Structures of Ln(II) and Ln(III) Dialkyls Derived from $\mathrm{LnI}_{2}(\mathrm{Ln}=\mathrm{Nd}, \mathrm{Tm}, \mathrm{Yb})$. Organometallics 2007, 26, 2646-2651; (b) Boyle, T. J.; Ottley, L. A. M.; Daniel-Taylor, S. D.; Tribby, L. J.; Bunge, S. D.; Costello, A. L.; Alam, T. M.; Gordon, J. C.; McCleskey, T. M. Isostructural neo-Pentoxide Derivatives of Group 3 and the Lanthanide Series Metals for the Production of $\mathrm{Ln}_{2} \mathrm{O}_{3}$ Nanoparticles. Inorg. Chem. 2007, 46, 3705-3713; (c) Sanden, T.; Gamer, M. T.; Fagin, A. A.; Chudakova, V. A.; Konchenko, S. N.; Fedushkin, I. L.; Roesky, P. W. Synthesis of Unsupported Ln-Ga Bonds by Salt Metathesis and Ga-Ga Bond Reduction. Organometallics 2012, 31, 4331-4339; (d) Boyle, T. J.; Neville, M. L.; Sears, J. M.; Cramer, R. E.; Rodriguez, M. A.; Alam, T. M.; Bingham, S. P. Synthesis, X-ray structures, and characterization of hexafluoro-iso-propoxide group 3 and lanthanide precursors. Polyhedron 2016, 118, 52-60.

(30) (a) Janjetovic, M.; Träff, A. M.; Ankner, T.; Wettergren, J.; Hilmersson, G. Solvent dependent reductive defluorination of aliphatic C-F bonds employing Sm(HMDS) 2. Chem. Commun. 2013, 49, 1826-1828; (b) Chciuk, T. V.; Hilmersson, G.; Flowers, R. A. Solvent-Dependent Substrate Reduction by $\left\{\mathrm{Sm}\left[\mathrm{N}\left(\mathrm{SiMe}_{3}\right)_{2}\right]_{2}(\mathrm{THF})_{2}\right\}$. An Alternative Approach for Accelerating the Rate of Substrate Reduction by Sm(II). J. Org. Chem. 2014, 79, 9441-9443.

(31) Jestilä, J. S.; Uggerud, E. Unimolecular Dissociation of Hydrogen Squarate $\left(\mathrm{HC}_{4} \mathrm{O}_{4}{ }^{-}\right)$and the Squarate Radical Anion $\left(\mathrm{C}_{4} \mathrm{O}_{4}{ }^{--}\right)$in the Gas Phase and the Relationship to CO Cyclooligomerization. J. Org. Chem. 2019, 84, 14005-14014.

(32) Bayer, U.; Anwander, R. Carbonyl group and carbon dioxide activation by rare-earth-metal complexes. Dalton Trans. 2020, 49, 17472-17493.

(33) Greenaway, A. M.; Dasgupta, T. P.; Koshy, K. C.; Sadler, G. G. A correlation between infrared stretching mode absorptions and structural angular distortions for the carbonato ligand in a wide variety of complexes. Spectrochim. Acta, Part A 1986, 42, 949-954.

(34) (a) Zhou, X.; Zhu, M. Insertions into lanthanide-ligand bonds in organolanthanide chemistry. J. Organomet. Chem. 2002, 647, 28-49; (b) Goudy, V.; Xémard, M.; Karleskind, S.; Cordier, M.; Alvarez Lamsfus, C.; Maron, L.; Nocton, G. Phenylacetylene and Carbon Dioxide Activation by an Organometallic Samarium Complex. Inorganics 2018, 6, 82; (c) Simler, T.; Feuerstein, T. J.; Yadav, R.; Gamer, M. T.; Roesky, P. W. Access to divalent lanthanide NHC complexes by redox-transmetallation from silver and $\mathrm{CO}_{2}$ insertion reactions. Chem. Commun. 2019, 55, 222-225; (d) Bayer, U.; Werner, D.; Maichle-Mössmer, C.; Anwander, R. Effective and Reversible Carbon Dioxide Insertion into Cerium Pyrazolates. Angew. Chem. Int. Ed. 2020, 59, 5830-5836.

(35) Maier, G.; Heider, M.; Sierakowski, C. Sind pyrazolin-3,5-dione als vorstufen für carbene geeignet ? Tetrahedron Lett. 1991, 32, 1961-1962.

(36) Silverstein, R. M.; Webster, F. X.; Kiemle, D. Spectrometric Identification of Organic Compounds, 7th Edition; John Wiley \& Sons: Hoboken, NJ, 2005.

(37) Frey, A. S. P.; Cloke, F. G. N.; Coles, M. P.; Maron, L.; Davin, T. Facile Conversion of $\mathrm{CO} / \mathrm{H}_{2}$ into Methoxide at a Uranium(III) Center. Angew. Chem. Int. Ed. 2011, 50, 6881-6883.

(38) (a) Serratosa, F. Acetylene diethers: a logical entry to oxocarbons. Acc. Chem. Res. 1983, 16, 170-176;

(b) Gleiter, R.; Werz, D. B. Alkynes Between Main Group Elements: From Dumbbells via Rods to Squares and Tubes. Chem. Rev. 2010, 110, 4447-4488. 